\title{
Cellular Toxicity and Immunological Effects of Carbon-based Nanomaterials
}

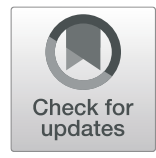

Xia Yuan, Xiangxian Zhang, Lu Sun, Yuquan Wei and Xiawei Wei

\begin{abstract}
Background: Carbon nanomaterials are a growing family of materials featuring unique physicochemical properties, and their widespread application is accompanied by increasing human exposure.

Main body: Considerable efforts have been made to characterize the potential toxicity of carbon nanomaterials in vitro and in vivo. Many studies have reported various toxicology profiles of carbon nanomaterials. The different results of the cytotoxicity of the carbon-based materials might be related to the differences in the physicochemical properties or structures of carbon nanomaterials, types of target cells and methods of particle dispersion, etc. The reported cytotoxicity effects mainly included reactive oxygen species generation, DNA damage, lysosomal damage, mitochondrial dysfunction and eventual cell death via apoptosis or necrosis. Despite the cellular toxicity, the immunological effects of the carbon-based nanomaterials, such as the pulmonary macrophage activation and inflammation induced by carbon nanomaterials, have been thoroughly studied. The roles of carbon nanomaterials in activating different immune cells or inducing immunosuppression have also been addressed.

Conclusion: Here, we provide a review of the latest research findings on the toxicological profiles of carbon-based nanomaterials, highlighting both the cellular toxicities and immunological effects of carbon nanomaterials. This review provides information on the overall status, trends, and research needs for toxicological studies of carbon nanomaterials.
\end{abstract}

Keywords: Cytotoxicity, Carbon nanomaterial, Macrophage, Immunological effects

\section{Introduction}

Nanotechnology has developed rapidly due to the expanding needs of many fields, including industry, agriculture, medicine and electronics [1]. Carbon-based nanomaterials represent the most promising products of nanotechnology, with fascinating properties that make them candidates for a variety of applications from drug delivery to electronics [2].

Carbon nanomaterials are a growing family of materials of different formations, such as black nanoparticles, fullerenes, carbon nanotubes (CNTs), fibres, and other related forms [3-8]. For instance, carbon black (CB) nanoparticles are traditional nanosized carbonaceous nanomaterials with a morphology consisting of grape-like aggregates of highly fused spherical particles, while carbon

\footnotetext{
* Correspondence: xiaweiwei@scu.edu.cn

Laboratory of Aging Research and Cancer Drug Target, State Key Laboratory of Biotherapy and Cancer Center, National Clinical Research Center for Geriatrics, West China Hospital, Sichuan University, No. 17, Block 3, Southern Renmin Road, Chengdu, Sichuan 610041, People's Republic of China
}

black is a quasi-graphitic form of nearly pure elemental carbon and presents as a major part of the ambient air pollution $[9,10]$. C-fullerenes (C60) are characterized by symmetrical closed-cage structures that consist of 60 carbon atoms arranged in the shape of a soccer ball [10]. CNTs are fibrous materials with high aspect ratios and needle-like shapes, sharing physical similarities with asbestos fibres [11]. CNTs exist in two principle forms, namely, single-walled CNTs (SWCNTs) and multiwalled CNTs (MWCNTs), and can assume a wide variety of derived structures, such as horns, loops and peapods [12]. Single-walled carbon nanohorns (SWCNHs) are horn-shaped single-walled tubules with cone angles of approximately $20^{\circ}$. SWCNHs are synthesized by laser ablation and are essentially metal-free with high purity [13]. In addition, nanographite (NG), also called graphite nanoplatelets, is a one-atom-thick and two-dimensional sheet of sp2-bonded carbon atoms [14]. Each type of carbonaceous nanomaterial has a distinguishable shape.

(c) The Author(s). 2019 Open Access This article is distributed under the terms of the Creative Commons Attribution 4.0 International License (http://creativecommons.org/licenses/by/4.0/), which permits unrestricted use, distribution, and reproduction in any medium, provided you give appropriate credit to the original author(s) and the source, provide a link to the Creative Commons license, and indicate if changes were made. The Creative Commons Public Domain Dedication waiver (http://creativecommons.org/publicdomain/zero/1.0/) applies to the data made available in this article, unless otherwise stated. 
In addition to manufactured nanoscale carbonaceous materials, naturally occurring carbonaceous particulates range from 1 to $100 \mathrm{~nm}$ in size exist. For instance, these materials exist in the emissions from certain combustion processes, such as the burning of methane and propane $[12,15]$. Numerous studies have endeavoured to evaluate the health impact of occupational and environmental exposure to carbon nanomaterials [12, 16-19]. Studies on air pollution and mineral dust particles demonstrated that inhaled particles with a size $<100 \mathrm{~nm}$ caused lung injury through reactive oxygen species (ROS), cell damage and inflammation [20-23].

In vitro models have been developed for cytotoxicity studies to eliminate some variables in animal studies so that researchers could achieve better control over experimental conditions. A number of studies evaluated the harmful effects of carbon nanoparticles on various cell types, and as the first-line of defence against foreign particles, macrophages were mostly studied. Previous studies reported various toxic effects of carbon nanomaterials, including ROS generation, DNA damage, lysosomal damage, mitochondrial dysfunction and eventual cell death via apoptosis or necrosis [24-26]. The different results of the cytotoxicity of carbon-based materials might be related to many factors, such as the differences in the physicochemical properties or structures of carbon nanomaterials, types of target cells and methods of particle dispersion.

Despite the cellular toxicity, the immunological effects of carbon-based nanomaterials have been thoroughly studied. The immune system, as the first-line of defence in the human body, recognizes foreign agents and subsequently triggers immune responses [27]. The immune system is classified into innate and adaptive immune systems. The former functions as the first-line of defence, relying on the complement system and phagocytic cells at the forefront. Adaptive immunity proceeds through specific long-lasting mechanisms due to $\mathrm{T}$ and $\mathrm{B}$ lymphocytes [28, 29]. Regarding the immunological effects of carbon-based nanomaterials, the issues of pulmonary macrophage activation and inflammation induction are fully addressed. In addition, as nanoparticles (NPs) might enter the human body, including the lungs, the cardiovascular system, the liver and even the brain, through inhalation $[20,30]$, other adverse effects of carbon nanomaterials in vivo have also been characterized. The interactions of NPs with biological systems might generate toxicity related to their small size, large surface area and large surface reactivity [31, 32]. For example, relevant studies demonstrated that SWCNTs induced acute and chronic pulmonary pathologies [33], and systematic damage was detected in the blood chemistry [34], the liver [35] and the cardiovascular system [36]. Notably, ultrafine particles were capable of entering the bloodstream by crossing the alveolar-capillary barrier. After intravenous injection, SWCNTs can cross the blood-brain barrier and have been observed to enter the brain [37]. Moreover, special attention should be paid to the interaction of CNTs with components of the immune system. In the past decade, great effort has been made to shed light on the immunological properties of carbon-based nanomaterials [38, 39]; nevertheless, numerous questions remain because of the complexity of immune defense mechanisms.

\section{Main text}

\section{Cellular Toxicity of Carbon-based Nanomaterials in Vitro}

Here, we present a summary of current research efforts regarding the cytotoxicity of carbon nanomaterials in different cell types, including macrophages, epithelial cells and lymphocytes. The cytotoxicity of carbon nanomaterials will be discussed in terms of the following three aspects: different structures of carbon nanomaterials in cytotoxicity studies, the underlying mechanisms of cytotoxicity and some potential factors influencing detected cytotoxicity. Carbon nanomaterials with various structures in this review are presented in Fig. 1 and their cytotoxicity is summarized in Table 1.

\section{Different structures of carbon nanomaterials used in cytotoxicity studies}

Single-walled carbon nanotubes It was reported that acid-functionalized SWCNTs (af-SWCNTs) displayed cytotoxicity in a concentration-dependent manner [40]. Another study showed that af-SWCNTs were engulfed by macrophages and then localized in lysosomes, leading to damaged mitochondrial function and inhibited phagocytic activity [41].

Multiwalled carbon nanotubes Concerning MWCNTinduced cellular toxicity, available data are inconsistent. One study evaluated the toxic properties of two different MWCNT types, and neither of them induced apoptosis of RAW264.7 cells, as determined by caspase 3/7 activity [42]. In contrast, another study demonstrated that acid-treated MWCNTs (acid-MWCNTs) and taurinefunctionalized MWCNTs (tau-MWCNTs) induced significant cell apoptosis and decreased cellular phagocytosis [43]. Different types of macrophages respond to MWCNTs distinctly. MWCNTs at any concentration from 3 to $30 \mu \mathrm{g} / \mathrm{ml}$ significantly induced cell death of murine bone marrow-derived dendritic cells (BMDCs), but for RAW264.7 cells, even $300 \mu \mathrm{g} / \mathrm{ml}$ MWCNTs presented no cytotoxicity [44]. 


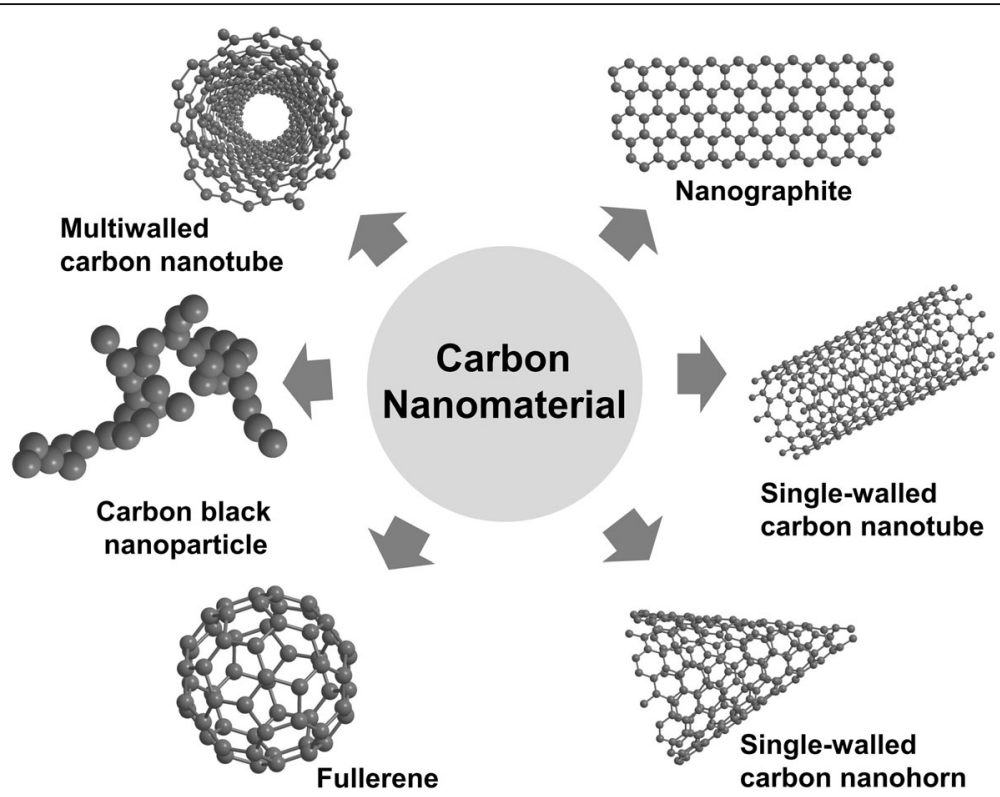

Fig. 1 Various carbon-based nanomaterials were reported to induce cytotoxicity. Carbon nanotubes (CNTs) are thin carbon filaments with cylindrical structure that comprise single or multiple graphene sheets, termed as single-wall carbon nanotubes (SWCNTs) and multiwall carbon nanotubes (MWCNTs), respectively. C-fullerene is a carbon allotrope organized solely by 60 carbon atoms with a polygonal structure. Carbon black nanoparticle is a traditional nanosized carbon-based nanomaterial of diameter between 10 to $100 \mathrm{~nm}$ with three nanometric dimensions. Nanographite, also called graphite nanoplatelet, is a one-atom-thick and two-dimensional sheet of sp2-bonded carbon atoms. Single-walled carbon nanohorns (SWCNHs) are horn-shaped single-walled tubules with cone angles of approximately $20^{\circ}$

Fullerene It was reported that fullerene (C60) did not cause cytotoxicity in alveolar macrophages as observed through an MTT assay [45]. Similarly, C60 presented very low cytotoxicity against human macrophages and did not act as a biological inducer to elicit inflammatory reactions [46].

Carbon black nanoparticles CB nanoparticles caused cell death in exposed human alveolar macrophages and RAW264.7 cells, characterized by a series of events including cell size enlargement, cell membrane rupture, caspase-1 activation, lactate dehydrogenase (LDH) leakage and IL-1 $\beta$ release [47]. Core/shell iron/carbon nanoparticles (Fe@CNPs) are applied in magnetic resonance imaging (MRI) and drug delivery. One study evaluated the cytotoxicity of variously functionalized Fe@CNPs (e.g., acrylic acid, pyrrolidone, primary amine and alkyl alcohol) in human embryonic kidney (HEK293) cells and human cervical carcinoma cells (C33A). Surface-modified Fe@CNPs triggered ROS generation to a similar degree, but only acrylic acid-functionalized Fe@CNPs induced cell death through the apoptotic pathway, suggesting that there is no association between ROS production and Fe@CNPs-induced cell apoptosis [48].

Nanographite It was reported that pristine graphene induced typical cell death, including apoptosis and necrosis, in RAW 264.7 macrophages [14]. The toxicity of NG,
CNTs and CB in RAW264.7 cells was compared through extracellular $\mathrm{LDH}$ release. Remarkable $\mathrm{LDH}$ release was observed only in the groups treated with CNT and NG at the highest dose, and NG produced stronger cellular toxicity than CNTs [9]. Due to the wide use of nanomaterials, many derivatives have been produced, and some of these derivatives have exhibited cellular toxicity $[49,50]$. Wan et al. reported that graphene oxides (GO) exerted adverse effects on murine peritoneal macrophages [40].

Single-walled carbon nanohorns A number of studies revealed the cytotoxicity of carbon nanomaterials under low-uptake conditions. Additionally, one study reported the response of RAW264.7 cells to high uptake of SWCNHs at $0.3 \mathrm{mg} / \mathrm{ml}$; excess SWCNH uptake caused cell death, including both apoptotic and necrotic mechanisms [51].

\section{The underlying mechanisms of cytotoxicity}

ROS MWCNTs induced cell apoptosis of 3T3 fibroblasts, bronchial epithelial cells and RAW macrophages as early as $6 \mathrm{~h}$ following exposure. The cellular responses to MWCNTs were characterized by ROS generation, lysosomal membrane destabilization (LMD), mitochondrial permeability and eventual cell death via the apoptotic pathway. ROS generation appeared to precede the other cellular responses, and increased ROS production was associated with LMD [52]. Another 


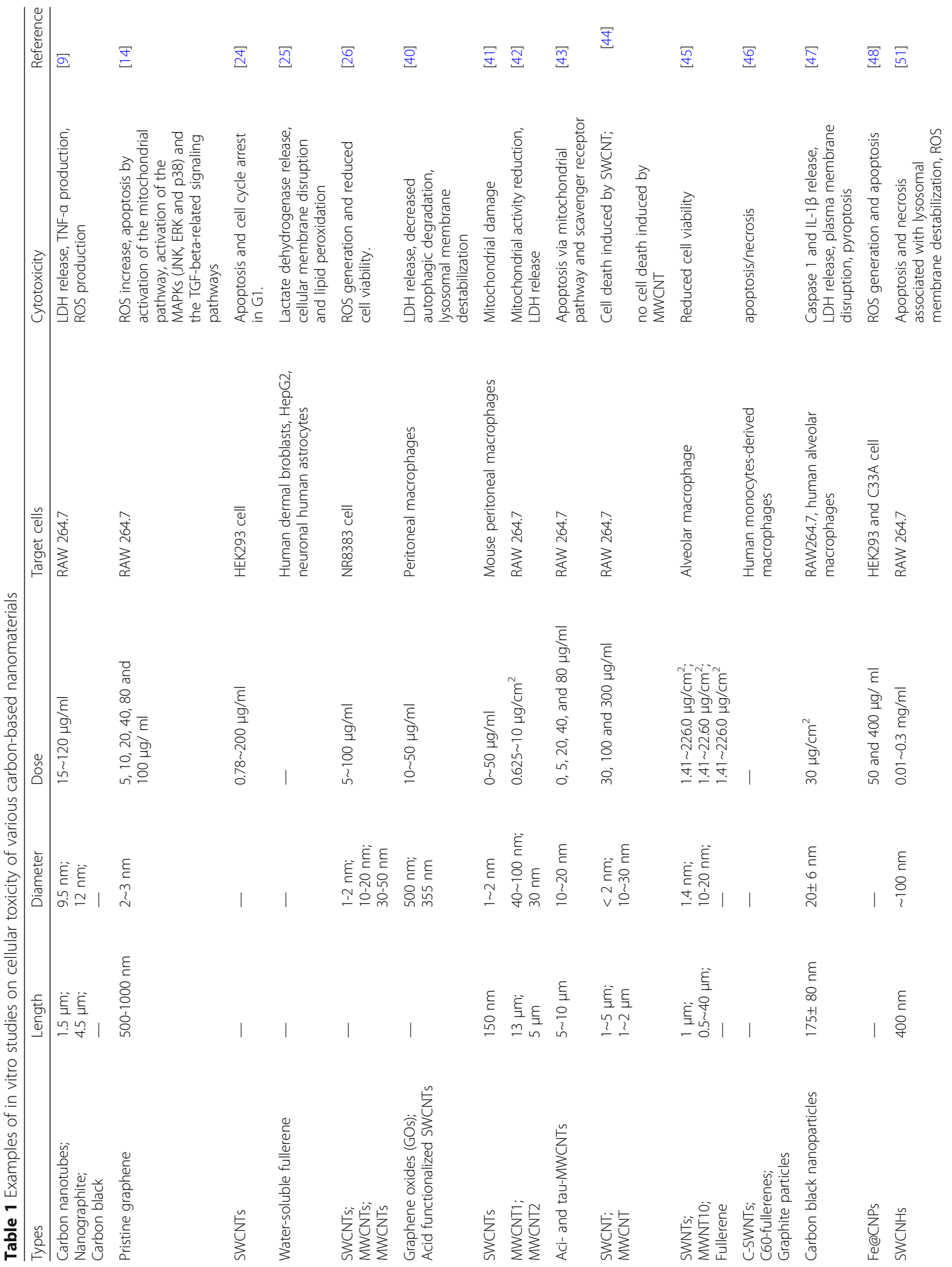




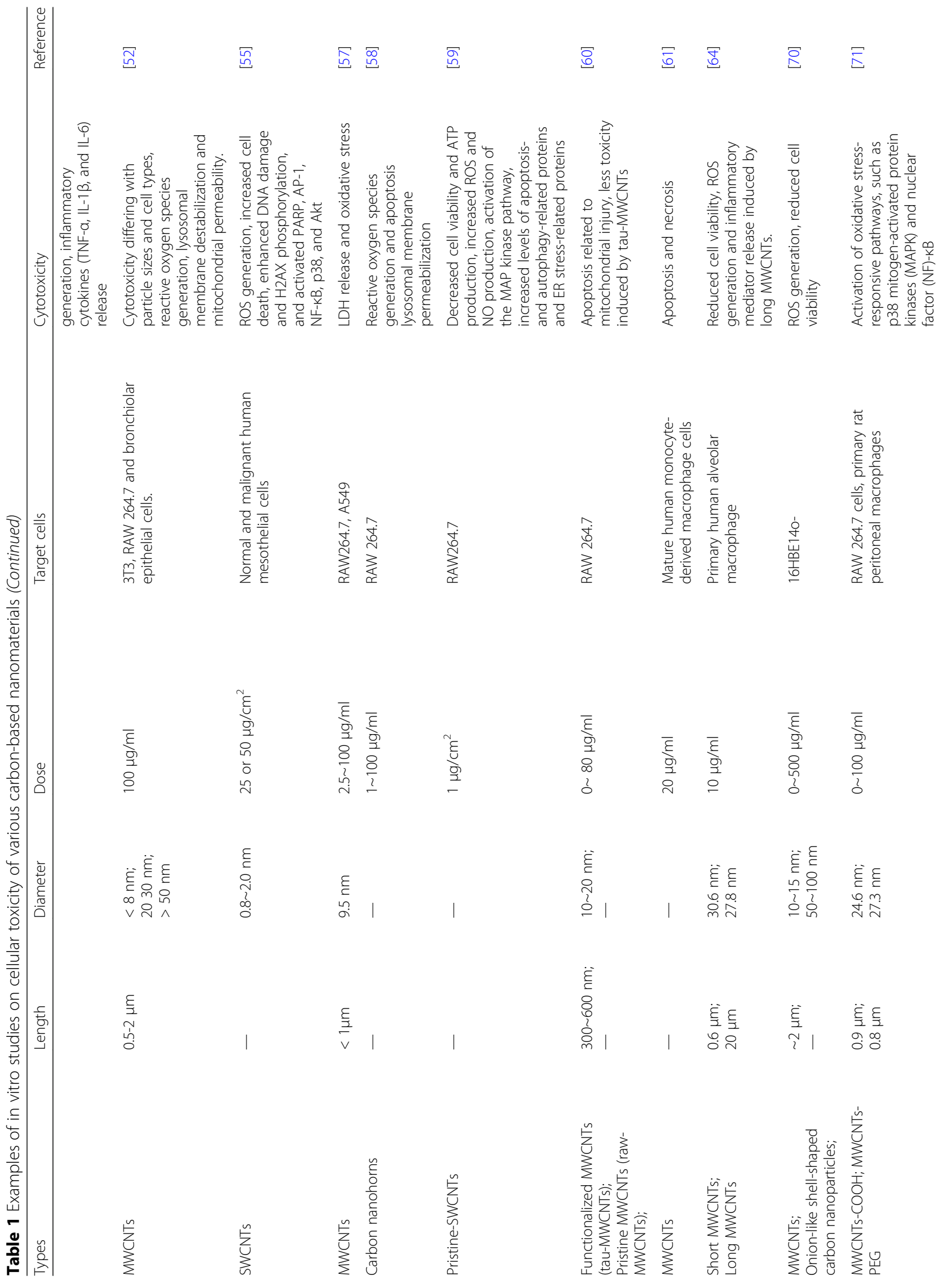




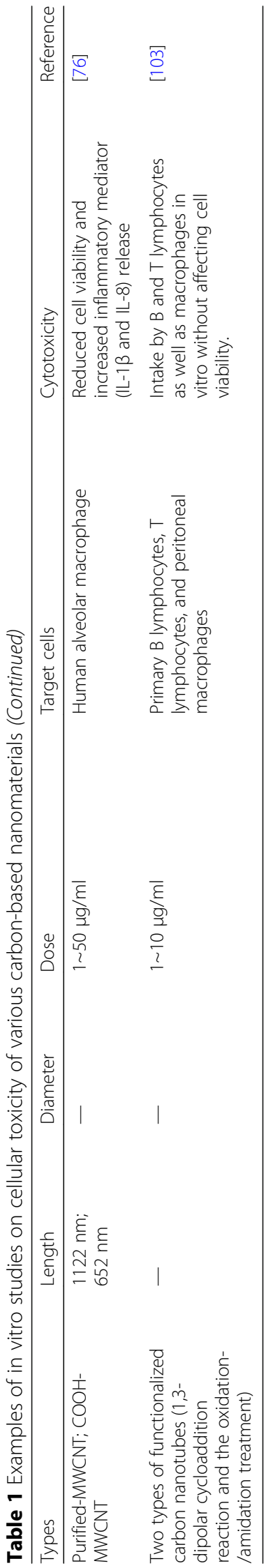


study reported ROS-activated, graphene-induced apoptosis that occurred through the MAPK and TGF- $\beta$ signaling pathways [14]. A comparison study of cellular toxicity between MWCNTs and onion-like shell-shaped carbon nanoparticles (SCNPs) was conducted on the human bronchial epithelial cell line 16HBE14o-. The presence of NAC, an antioxidant that acts as an ROS scavenger, restored cell viability remarkably, suggesting an association between ROS generation and cellular toxicity [53]. A number of studies have identified oxidative stress as a common mechanism of CNT-induced cell toxicity. SWCNTs induced oxidative stress and cellular toxicity in human epidermal keratinocytes [54], and incubation with SWCNTs triggered ROS generation and consequently cell death along with NF- $\mathrm{KB}$ and p38 activation [55]. The addition of dipalmitoylphosphatidylcholine (DPPC) increased the level of cellular ROS, whereas fetal calf serum (FCS) appeared to protect exposed cells against oxidative injury [56]. In response to MWCNT exposure, ROS production in A549 and RAW264.7 cells increased within minutes, peaking within an hour and decreasing after several hours. The dose-dependent cytotoxicity induced by MWCNTs might be closely related to increased oxidative stress [57].

Cell autophagy and lysosomal membrane damage Recently, lysosomal dysfunction emerged as a potential mechanism of nanomaterial toxicity. Additionally, a lysosome-based process known as cell autophagy was recognized as an important pathway of cell death, and a variety of nanomaterials have been demonstrated to induce autophagosome accumulation. Wan et al. shed light on the potential mechanism of carbon nanomaterial-induced cytotoxicity. The investigators measured the formation of autophagosomes via electron microscopy, pEGFP-LC3 transfection and Western blotting, and decreased autophagic degradation was observed. Lysosome disorders were often associated with autophagy dysfunction, and as expected, the researchers confirmed significant lysosome impairment of murine peritoneal macrophages upon SWCNT and graphene oxide exposure using FITC-dextran staining [40]. High-uptake of SWCNHs induced macrophage apoptosis and necrosis associated with lysosomal dysfunction, and internalized SWCNHs were located in lysosomes, as determined by labeling SWCNH with Alexa Fluor 488 and staining lysosomes with lysotracker red. The accumulation of SWCNH in lysosomes induces ROS generation, which in turn triggers lysosomal membrane damage, causing apoptosis and necrosis. Preloaded FITC-dextran (250 $\mathrm{kDa}$ ) diffusion from the lysosome to the cytoplasm upon SWCNH treatment confirmed lysosomal membrane rupture (LMR) or lysosomal membrane permeabilization (LMP) [51]. Exposure of macrophages to 1 to100 $\mu \mathrm{g} /$ $\mathrm{ml} \mathrm{CNTs}$ for $24 \mathrm{~h}$ or $48 \mathrm{~h}$ resulted in dose- and time-dependent apoptotic cytotoxicity. Furthermore, internalized CNTs were found to accumulate in lysosomes, inducing lysosomal membrane permeabilization followed by a release of cathepsins into the cytoplasm, which led to mitochondrial dysfunction and the generation of ROS [58].

Pyroptosis One study investigated an inflammasomedependent form of cell death induced by CB nanoparticles, identified as pyroptosis. It was characterized by membrane integrity loss and membrane pore formation, causing cell swelling and eventual cell lysis, but the exact mechanism remained unclear. In that study, exposure to $\mathrm{CB}$ nanoparticles resulted in inflammasome activation, caspase-1 cleavage and downstream IL-1 $\beta$ release. A caspase-1 inhibitor and a pyroptosis inhibitor both had protective effects on macrophage viability [47].

Apoptosis associated with the mitochondrial pathway and scavenger receptors Acid-MWCNTs and tauMWCNTs induced apoptosis of RAW264.7 via the mitochondrial pathway and scavenger receptor. Mitochondrial membrane potential decreased and cytochrome c leaked upon MWCNT treatment, and a specific inhibitor of caspase-9 prevented cells from undergoing apoptosis, indicating that the mitochondrial pathway might be involved in the mechanism of MWCNT-induced apoptosis. In addition, a nonspecific inhibitor of scavenger receptors (poly I) and the specific SR-A inhibitor 2F8 could restore MWCNT-treated RAW264.7 cells from apoptotic death significantly [43]. Similarly, pristine SWCNTs (p-SWCNTs) induced apoptosis in RAW264.7 cells through mitochondrial dysfunction, and ATP production decreased in a dose-dependent manner. Additionally, the generation of ROS was enhanced, and apoptosis- and autophagy-related proteins increased [59]. Tau-MWCNTs and raw-MWCNTs produced dose- and time-dependent cytotoxicity in the peritoneal macrophage cell line (RAW264.7) after treatment at different concentrations. Cytotoxicity was involved in the mitochondria-initiated pathway, whereby mitochondrial membrane potential decreased, cytochrome $\mathrm{c}$ was released from mitochondria, cytoplasm $\mathrm{Ca}^{2+}$ levels increased and ATPase activity was inhibited after MWCNT exposure [60].

Necrosis It was observed that unpurified MWCNTs entered cells actively and passively by insertion through the plasm membrane, resulting in cell necrosis rather than apoptosis. Decreased cell viability was detected via neutral red staining, MTT assays, confocal microscopy and TEM analysis. Cultures treated with purified MWCNTs (iron catalyst removed) exhibited comparable levels of cell death to those treated with unpurified MWCNTs [61]. In another study, purified SWCNTs induced a low percentage of cell death, apparently necrosis, in human monocyte-derived 
macrophages (HMMs). The morphology and structure of necrotic cells were observed by TEM images, and large bundles of SWCNTs were ingested by HMMs, localizing in lysosomes or possibly free in the cytoplasm [62]. The mechanisms of carbon nanomaterial-induced cytotoxicity are presented in Fig. 2.

\section{Potential factors influencing the cytotoxicity of carbon- based nanomaterials}

\section{Physical properties of carbon nanomaterials}

Length Long MWCNTs were cytotoxic to macrophages, whereas short CNTs did not induce any cytotoxicity [63]; additionally, long MWCNTs $(20 \mu \mathrm{m})$, but not short ones $(0.6 \mu \mathrm{m})$ significantly decreased cell viability and increased ROS generation in human alveolar macrophages, indicating that MWCNT length is a critical determinant of adverse bioreactivity [64]. Sato et al. evaluated the influence of material length on the cytotoxicity of CNTs against the human acute monocytic leukaemia cell line (THP-1). Two kinds of CNTs with average lengths of $220 \mathrm{~nm}$ and $825 \mathrm{~nm}$ were prepared. The authors noted that 825-CNTs triggered stronger inflammation than 220-CNTs since the macrophages could envelope 220 -CNTs more readily than $825-\mathrm{CNTs}$ [65]. In a toxicity study on short and long CNTs, both were phagocytized by NR8383 rat alveolar macrophages, but long CNTs exerted more significant biological effects, such as cell death, ROS generation and MIP- $1 \alpha$ expression. The in vivo results showed that long CNTs induced acute lung inflammation, whereas short CNTs caused slower pulmonary responses [66].

Size Nanotoxicological research has demonstrated that the toxicity of nanomaterials is inversely related to particle size. One study assessed the cytotoxicity of MWCNTs of various sizes (diameters $<8 \mathrm{~nm}, 20-30 \mathrm{~nm}$ and $>50 \mathrm{~nm}$; same length, $0.5-2 \mu \mathrm{m}$ ) in 3T3 fibroblasts, bronchial epithelial cells and RAW macrophages. In the study, MWCNTs presented the same mild degree of cytotoxicity in 3T3 fibroblasts as in bronchial epithelial cells, and MWCNTs $<8 \mathrm{~nm}$ were more toxic than larger-diameter materials. In contrast, MWCNTs $>50$ $\mathrm{nm}$ were more toxic than small-diameter materials in RAW264.7 cells [67]. Another study reported that thin MWCNTs (diameter $\sim 50 \mathrm{~nm}$ ) with high crystallinity and needle-like shape showed mesothelial cell membrane piercing and induced cytotoxicity and carcinogenicity in mesothelial cells. In contrast, thick MWCNTs (diameter $\sim 150 \mathrm{~nm}$ ) were less toxic, inflammogenic and carcinogenic [68]. Two samples of MWCNTs of different diameters $(9.4$ vs $70 \mathrm{~nm})$ were prepared. Thinner MWCNTs appeared significantly more toxic than the thicker ones, by evidence of increased LDH activity, ROS production and intracellular GSH depletion [69]. In another study, the authors investigated the biological oxidative effects of carbon black nanoparticles with mean aerodynamic diameters of 14, 56 and $95 \mathrm{~nm}$ in rat alveolar epithelial cells and alveolar macrophages. The results showed that smaller particles can induce more prominent oxidative

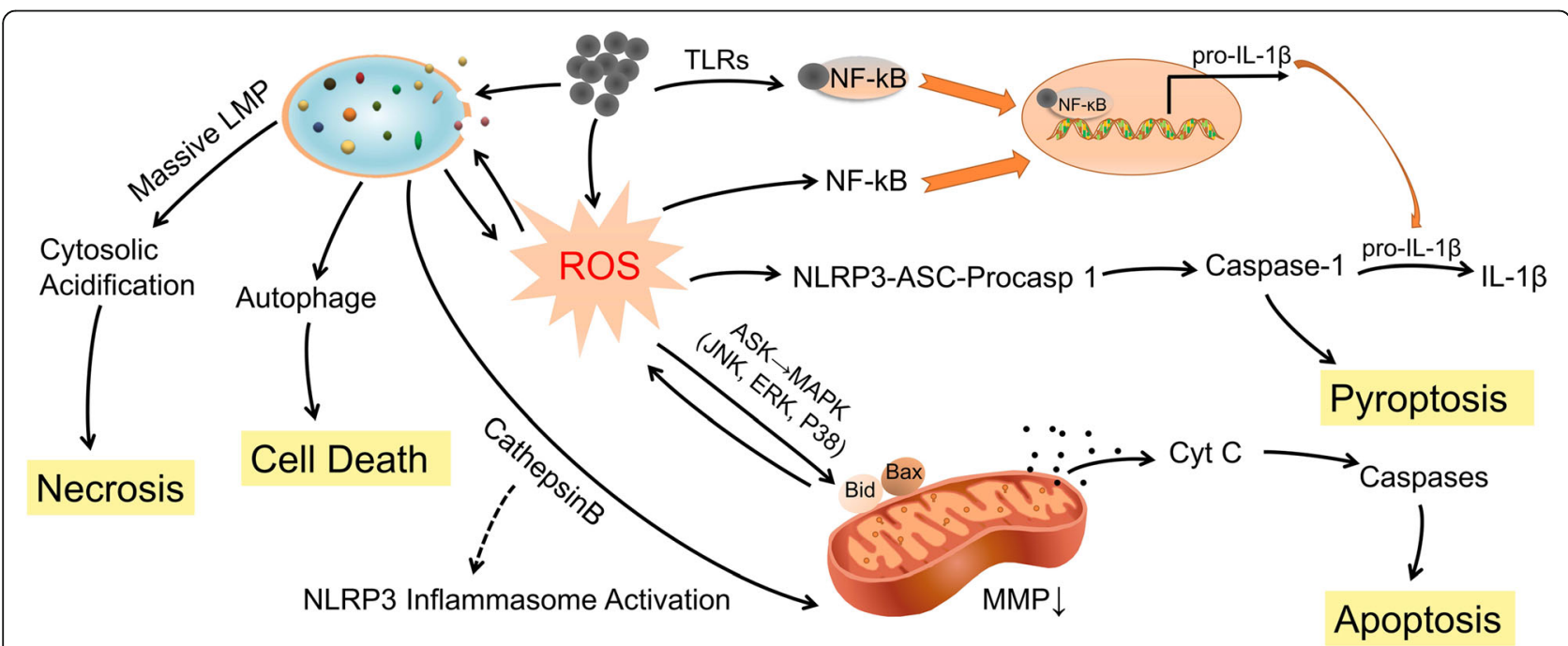

Fig. 2 The mechanisms by which carbon-based nanoparticles induce cytotoxicity of macrophages. Exposure of macrophages to carbon nanomaterials triggers a cascade of cellular and molecular events, such as ROS generation and lysosome damage, which serve as the mechanisms underlying carbon nanomaterial-induced cell death, including necrosis, apoptosis and pyroptosis. Carbon nanomaterials cause the mitochondrial dependent apoptotic cascades through ROS-activated MAPKs pathway. ROS could activate several transcription factors, such as NF-kB that regulates the inflammatory response. Carbon nanomaterials induce lysosomal membrane permeabilization (LMP), resulting in the translocation of cathepsins to the cytoplasm. ROS and LMP were reciprocal causation generating an amplification loop. LMP could potentially cause autophagy dysfunction. And inflammasomedependent pyroptosis was initiated characterized by cleavage of caspase 1 and downstream IL-1 $\beta$ release 
stress in vitro, which may be mediated by the surface function of the particles [32].

Shape Carbon nanomaterials with different geometric structures exhibit quite different toxic profiles. A cytotoxicity test protocol for SWCNTs, MWCNTs and C60 was performed to illustrate the influence of different geometric structures of carbon nanomaterials on cytotoxicity. The cytotoxicity of SWCNTs was significantly greater than that of MWCNTs at the same concentration, and both SWCNTs and MWCNTs induced profound toxic effects at a lower concentration, whereas no toxic effect was observed in the C60 group [45]. One study evaluated the toxicity of af-SWCNTs and graphene oxides in primary murine peritoneal macrophages. The results showed that both of the materials induced cell death, autophagosome accumulation and lysosome impairment of macrophages. Although they shared similarities in chemical composition and surface functional groups, graphene oxides were more toxic than af-SWCNTs [40]. The authors claimed that the difference in the toxic potency of graphene oxides and acid-functionalized SWCNTs may be attributable to their distinct physical features. SWCNTs have a tubular shape, tending to penetrate membranes, whereas the flat shape of graphene oxides provides stronger contact with cell membranes, resulting in higher toxicities. In another study [70], the investigators found that the cytotoxicity of differently shaped carbon nanomaterials might not be simply linked to the shapes. The authors found that MWCNTs of elongated shape were more toxic than carbon nanoparticles of spherical shape. The toxicity of carbon nanomaterials might follow the general sequence order as illustrated by relevant studies as follows: fullerenes < carbon black nanoparticles < MWCNTs < SWCNTs $<$ graphene.

Surface functionalization of nanomaterials PEG-functionalized MWCNTs (MWCNTs-PEG) and carboxylated MWCNTs (MWCNTs-COOH) were used to investigate the effect of noncovalent or covalent functionalization of MWCNTs on their cytotoxicity. The results showed that MWCNTs-PEG were less cytotoxic than MWCNTs$\mathrm{COOH}$. The underlying mechanism was elucidated: lower cellular uptake of MWCNTs-PEG resulted in less generation of ROS and less activation of oxidative stress-responsive pathways such as the p38 MAPK and NF-kB pathways. The study demonstrated that surface functionalization of MWCNTs might alter ROS-mediated cytotoxicity and modulate apoptotic signaling pathways [71].

As previously described, MWCNT carboxylation resulted in damage to the carbon framework and promoted CNT degradation since carboxyl groups combined with associated defect sites, facilitating interaction with lysosomal enzymes [72-74]. Additionally, the damage to the CNTs framework triggered increased degradation in simulated phagolysosomal fluid [75]. A comparative toxicity experiment was performed between acid-purified MWCNTs and concentrated acid-functionalized MWCNTs-COOH [76]. As expected, MWCNTs-COOH yielded less cytotoxicity than MWCNTs, whereas the latter reduced cell viability and increased the release of inflammatory mediators [76]. The binding of human blood proteins to SWCNTs reduced the toxicity of the latter in THP-1 cells and human umbilical vein endothelial cells (HUVECs) [6]. Not only size and dispersion in aqueous solution, but also the degree of functionalization by protein influenced the toxicity of carbon nanomaterials. The cytotoxic effect of CNTs functionalized with a 46-kDa surface protein was evaluated in J774A macrophages. The results showed that functionalized P46CNTs displayed grade-dependent cytotoxicity, that is, P46-CNTs of high grade were more toxic than those of low grade [77]. Additionally, the nature of the functional protein influenced the cytotoxicity of nanoparticles. Functionalization with even a small amount of the $220-\mathrm{kDa}$ lectin (L220), an immuno-modulatory molecule, decreased the cytotoxicity of CNTs, whereas fluorescein isothiocyanatefunctionalized CNTs (FITC-CNTs) presented a greater toxic effect on macrophages, mainly characterized by necrosis [78].

Tau-MWCNTs are MWCNTs that have been modified with taurine on the surface and are more water-soluble than raw-MWCNTs. Cytotoxicity assessment demonstrated that tau-MWCNTs exhibited lower cytotoxicity than raw-MWCNTs [60]. Additionally, it was reported that functionalized SWCNTs that were water-soluble showed reduced cytotoxicity compared to nonfunctionalized SWCNTs in human dermal fibroblasts [79]. Several studies have reported that pristine CNTs are insoluble and induce cell death in vitro. Chemically modified CNTs are highly water-soluble, and their cytotoxicity is associated with their degree of functionalization [45, 79-81].

Metal impurities Manufactured SWCNTs usually contain significant amounts of metal impurities, such as iron, which may act as a catalyst of oxidative stress [82]. Recent studies have shown that metal impurities play a critical role in cytotoxicity and that metal-containing SWCNTs are likely more toxic than metal-free nanoparticles [83]. The purification of CNTs might alter their cytotoxicity, that is, purified CNTs exhibited less toxicity than unpurified ones. However, previous studies demonstrated that the cytotoxic potential was related to the groups added and the purification process applied to the CNTs [78]. In contrast, there is evidence that removing metal catalyst remnants by concentrated acid functionalization does not reduce the toxic potential [53]. Iron catalyst particles generated free radicals through a Fenton-like reaction, leading to lipid peroxidation of the 
plasma membrane. Thus, SWCNTs purified by acid treatment induced increased toxicity in human monocyte-derived macrophages [62]. It was found that iron-rich (nonpurified) SWCNTs (26 wt.\% of iron) presented stronger redox activity than iron-stripped (purified) SWCNTs (0.23 wt.\% of iron) because iron might function as a catalyst of oxidative stress, thus causing increased cytotoxicity in RAW264.7 cells [84].

\section{Immunological Effects of Carbon-based Nanomaterials}

Carbon nanomaterials are increasingly being used in medical applications. Different NPs stimulate or interact with various immune cells and different pathways, and the immune response partly depends on the structure and chemistry of the particles [38]. In this section, we highlighted the current findings concerning carbon nanomaterial-mediated immune cell responses in vitro and their immunological effects in vivo (summarized in Table 2).

\section{Carbon Nanomaterial-mediated Immune Cell Responses in Vitro \\ The effect on macrophages}

The majority of the works of carbon nanomaterial-mediated immune cell responses, including the effects on cellular uptake, cellular viability, and induction of inflammation, have been carried out on macrophages. Several studies have suggested that engineered nanoparticles might influence the cellular uptake of macrophages. For instance, shorter CNTs can be engulfed by different immune cells in vitro; however, long CNTs induced the so-called frustrated phagocytosis in macrophages, which triggered persistent inflammatory responses and increased the production of ROS and cytokines $[85,86]$. Internalisation of CNTs by immune cells is also a critical determinant in biomedical applications [87]. Macrophages, as typical phagocytes, are very attractive targets for selective drug delivery [88]. Poor recognition of CNTs by macrophages is prohibitive of macrophage-mediated "surveillance" [18, 89], whereas functionalization of CNTs increases their recognition by phagocytes and other cells [80, 90-92]. Apoptotic cells expose an anionic phospholipid, phosphatidylserine (PS), on the cell surface as the "eat-me" signal for recognition and uptake by macrophages [93]. In one study, PS-coated SWCNTs were recognized by different phagocytic cells (i.e., murine RAW264.7 macrophages, primary monocyte-derived human macrophages, dendritic cells, and rat brain microglia), and their uptake was suppressed by the PS-binding protein Annexin V. Additionally, PS coating changed the pro- and anti-inflammatory behaviours of macrophages induced by nanoparticles [88]. Another study demonstrated that phenylboronic acid (PB)-modified carbon dot nanoparticles could be taken up by macrophages with low toxicity and high efficiency compared to unmodified nanoparticles. The findings suggested that these modified nanoparticles are good candidates for delivering drugs to suppress or eliminate aberrant immune cells, such as tumour-associated macrophages [94].

Carbon nanomaterials reportedly exhibit harmful effects on macrophages. Macrophages play a key role in the ingestion of microorganisms and tissue homeostasis. One study revealed that the function of human monocyte-derived macrophages (HMDMs) might be comprised by SWCNTs due to suppressive effects. SWCNTs at non-cytotoxic concentrations suppressed HMDM chemotaxis and impaired the engulfment of apoptotic target cells by macrophages following pre-incubation with SWCNTs [95]. One in vitro study investigated the potential pathophysiological consequences of primary human alveolar macrophages exposed to long MWCNTs (20 $\mu \mathrm{m}$ in length) and short MWCNTs $(0.6 \mu \mathrm{m}$ in length). After a 24-hour treatment with long MWCNTs, alveolar macrophage viability decreased, superoxide levels increased, and inflammatory mediator release increased, and phagocytosis and migratory capacity of alveolar macrophages decreased [96]. In addition to causing cytotoxicity, pristine MWCNTs and functionalized MWCNTs with $\mathrm{COOH}$ and PEG reportedly induce significant production of inflammatory cytokines, including TNF- $\alpha, \mathrm{IL}-1 \beta$ and IL- 6 , at different concentrations from 25 to $200 \mu \mathrm{g} / \mathrm{ml}$ [97]. CB, short CNTs, long and tangled CNTs, and long and needle-like CNTs were used to compare their potencies to induce secretion of IL-1 family cytokines. The authors found that long and needle-like CNTs activated the secretion of IL- $1 \beta$ and IL- $1 \alpha$ from HMDMs, dependent on NLRP3 inflammasome activation. Moreover, it was noted that ROS production and cathepsin $\mathrm{B}$ activation were involved in CNT-induced NLRP3 inflammasome activation [98].

\section{The effect on lymphocytes}

Lymphocytes are responsible for the antigen-specific and innate characteristics of the immune response. Several reports have elaborated on the positive or negative modulation effects of carbon nanomaterials on the cell function of lymphocytes. One study investigated the impact of functionalized CNTs on T and B lymphocytes and natural killer (NK) cells. The results showed that strong activation was induced in NK cells [99]. In one study, the authors found that CNTs at low doses $(0.00-0.1 \mu \mathrm{g} / \mathrm{ml})$ did not induce cellular toxicity, but they enhanced lymphocyte-mediated cytotoxicity against multiple human cell lines through NF- $\mathrm{KB}$ activation in lymphocytes. Additionally, CNTs induced an increase in secretion of IFN- $\gamma$ and TNF- $\alpha$ from lymphocytes [100]. Another study reported that SWCNTs at concentrations 


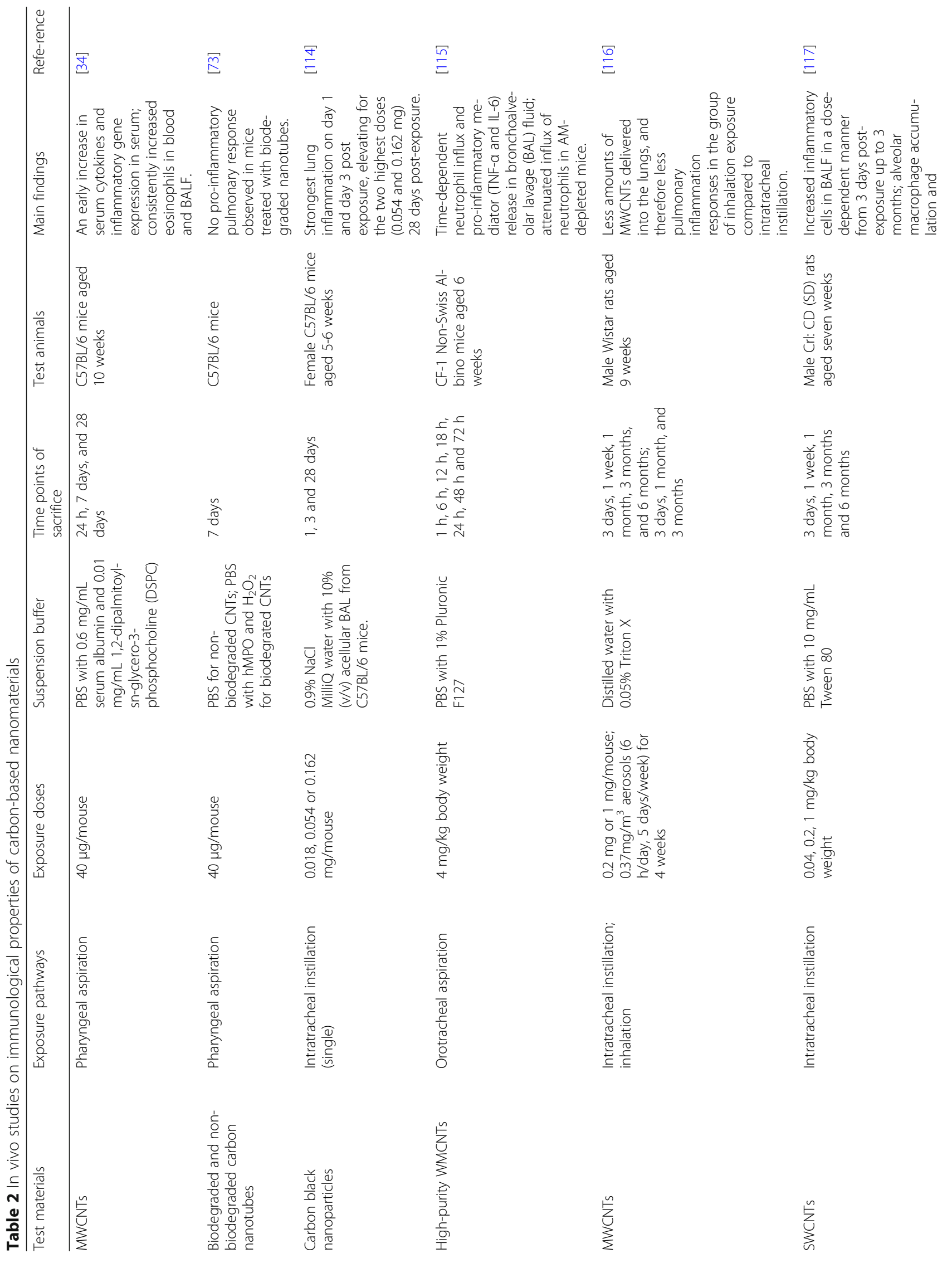




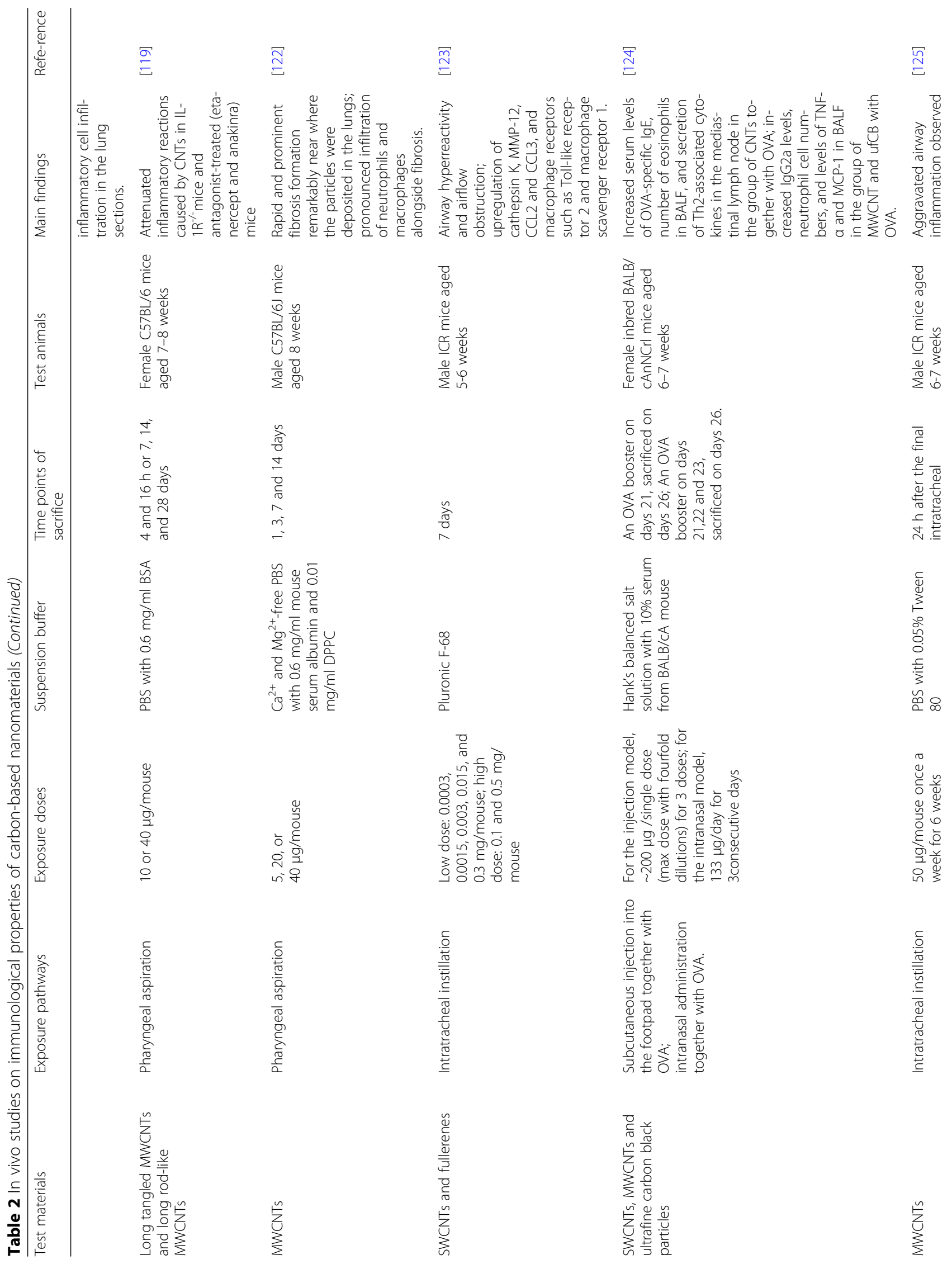




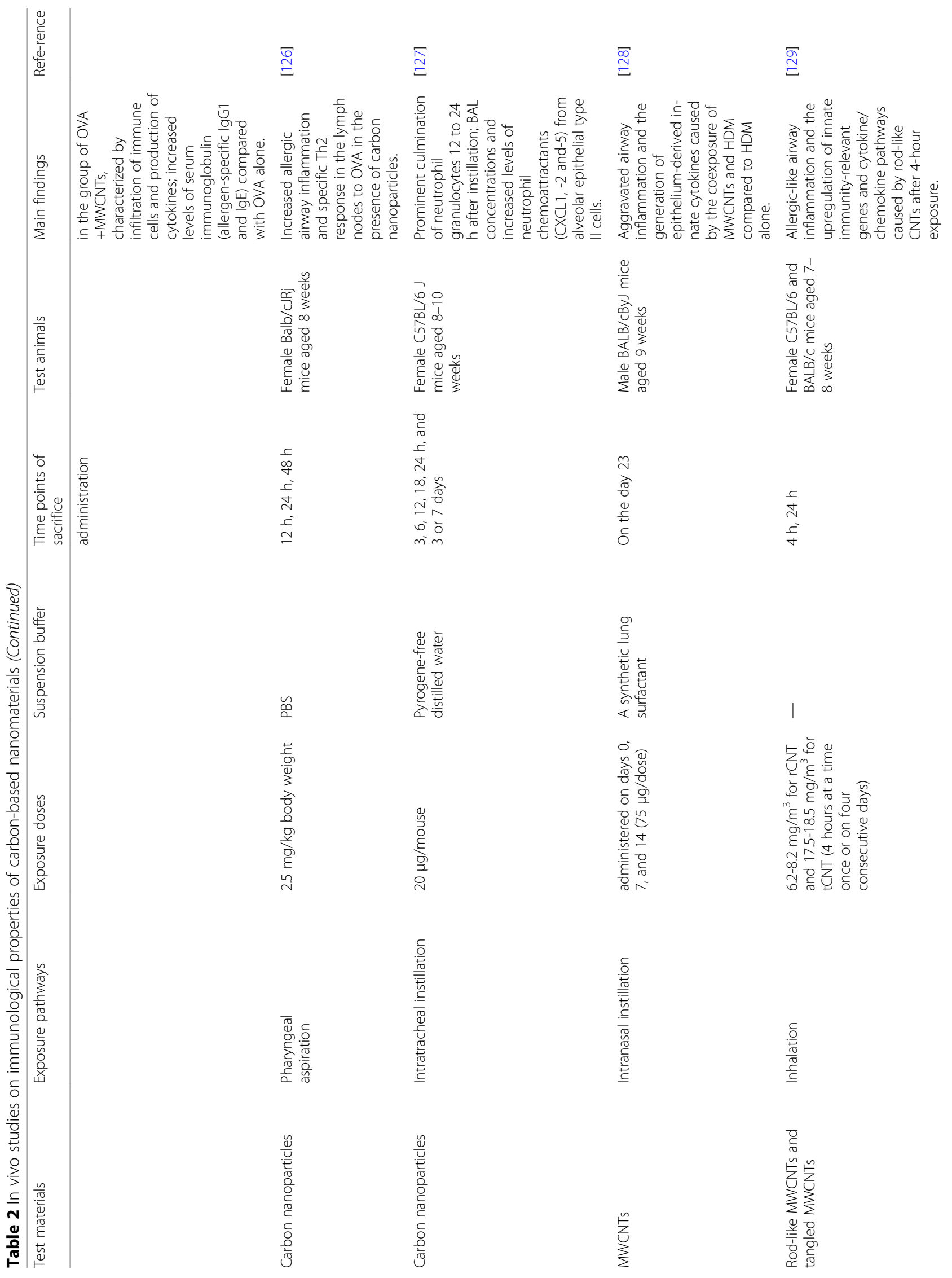




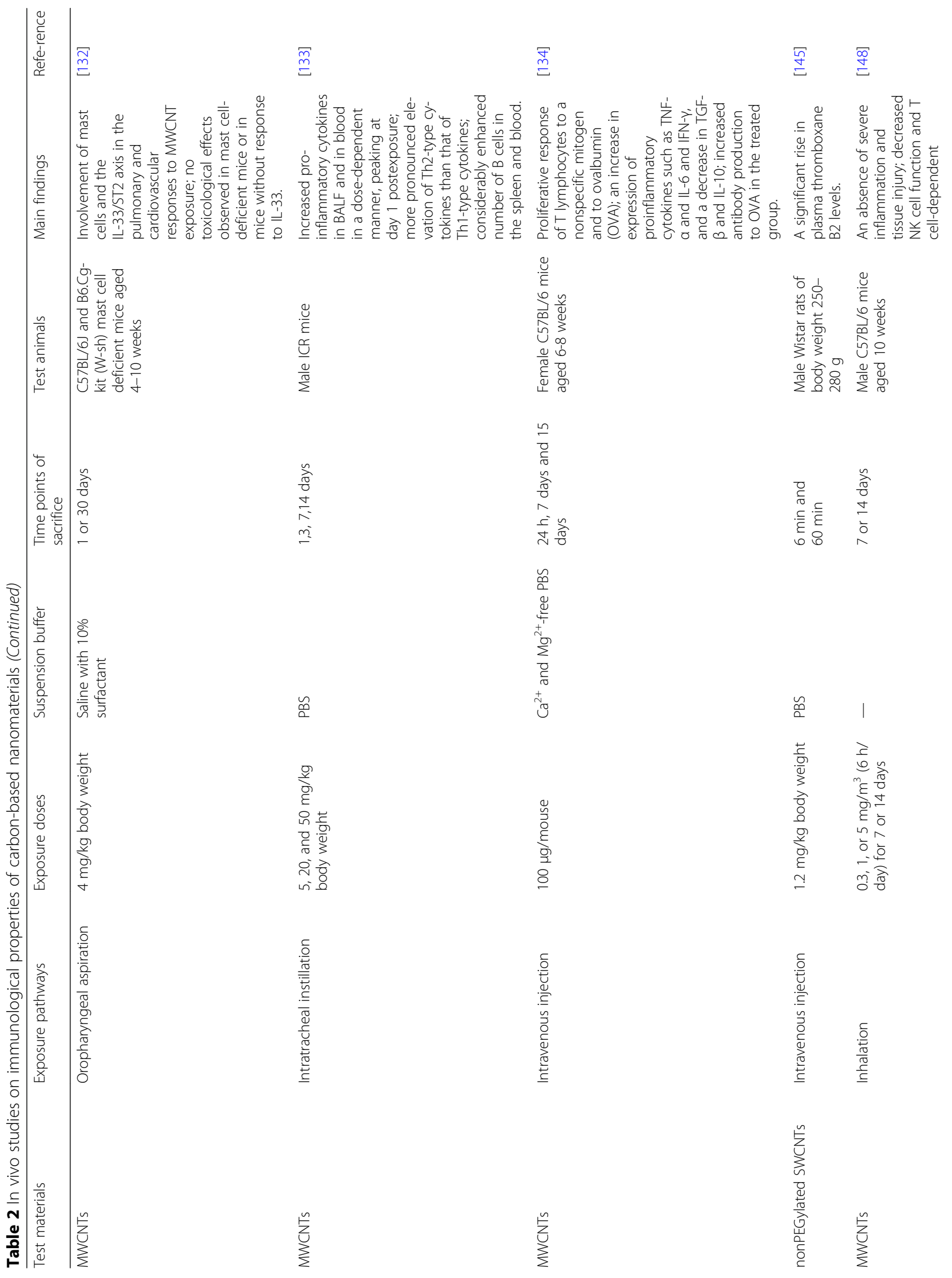




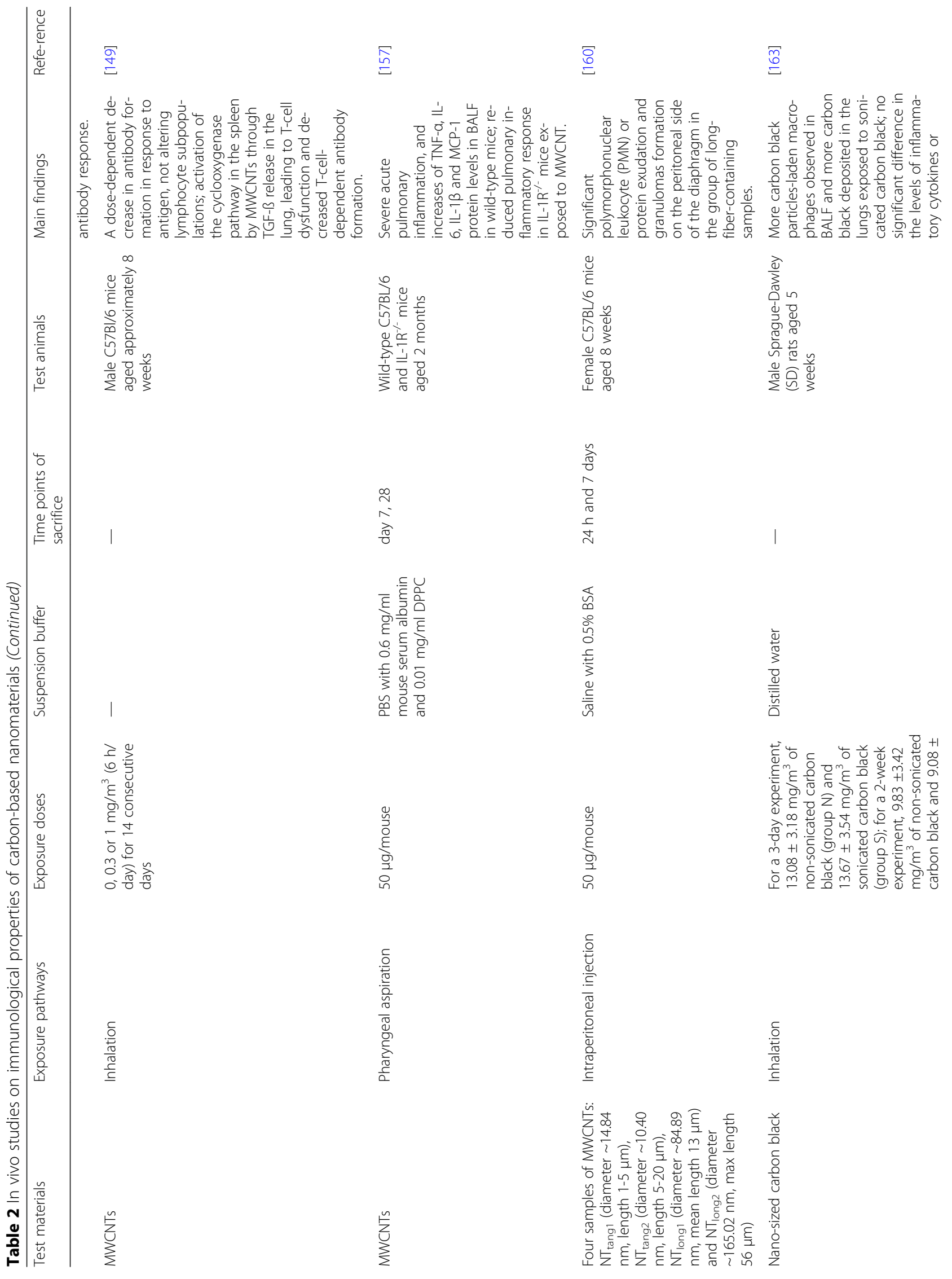




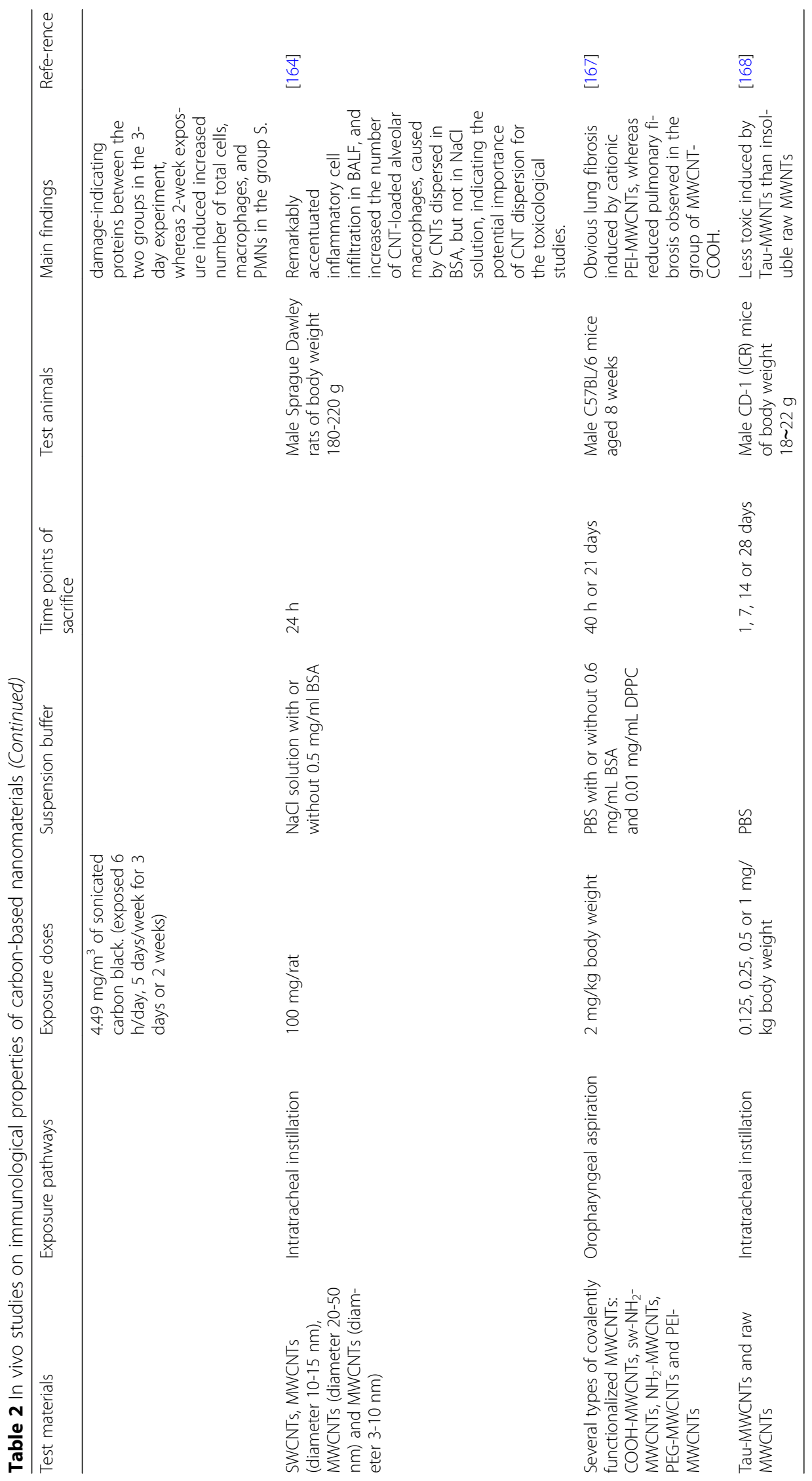


of 1 and $10 \mu \mathrm{g} / \mathrm{ml}$ had no proliferation effects on spleen cells, and SWCNTs at 25 or $50 \mu \mathrm{g} / \mathrm{ml}$ promoted the proliferation of spleen cells. In turn, SWCNTs inhibited T lymphocyte proliferation at higher concentrations and inhibited LPS-induced B lymphocyte proliferation at concentrations of 1, 10, 25 and $50 \mu \mathrm{g} / \mathrm{ml}$. Moreover, they significantly decreased NK cell activity [101].

Carbon nanomaterial-induced cytotoxicity in lymphocytes was reported. In one study, the authors found that oxidized MWCNTs $(400 \mu \mathrm{g} / \mathrm{ml})$ induced a massive loss of cell viability of human $\mathrm{T}$ cells through programmed cell death, whereas pristine MWCNTs were less toxic [102]. In contrast, another study found that two types of functionalized CNTs (the 1,3-dipolar cycloaddition reaction and the oxidation/amidation treatment, respectively) were taken up by $\mathrm{B}$ and $\mathrm{T}$ lymphocytes and macrophages in vitro, without affecting cell viability [103].

\section{The effect on dendritic cells}

Dendritic cell-based immunotherapy is an important type of anticancer strategy and has generated promising results in clinical trials $[104,105]$. In one study, the authors demonstrated that MWCNTs conjugated to tumour proteins increased the uptake of tumour antigens by human DCs and induced anticancer responses of DCs in vitro [106]. The inflammatory potential of carbon nanoparticles represents a critical issue regarding their biomedical applications. One study explored the inflammatory properties of CNTs and carbon nano-onions (CNOs) in dendritic cells. Highly purified CNTs and CNOs (p-CNTs and p-CNOs) failed to induce dendritic cell maturation or secretion of inflammatory cytokines (IL-6 and TNF- $\alpha$ ). However, $\mathrm{p}-\mathrm{CNTs}$ and $\mathrm{p}-\mathrm{CNO}$ s promoted the secretion of IL- $1 \beta$ by dendritic cells in a NLRP3- and dose-dependent manner, whereas CNOs exhibited a weaker inflammatory profile. Remarkably, the benzoic acid functionalization of p-CNTs and $\mathrm{p}$-CNOs reduced their inflammatory activity, which was characterized by the reduced secretion of IL-1 $\beta$ [107].

\section{The effect on other immune cells}

Evidence of carbon nanomaterial-mediated cellular responses in other types of immune cells is insufficient. One study investigated the impact of functionalized CNTs on monocytes in vitro. The results showed that strong activation was induced in monocytes by CNTs [99].

\section{Immunological Effects of Carbon-based Nanomaterials in Vivo}

\section{Pulmonary macrophage activation and inflammation induction}

Alveolar macrophages, as resident phagocytes in the lung, play a central role in particle removal by nonspecific phagocytosis. The first response of macrophages against inhaled particles is to recognize these particles by cell surface receptors, such as the mannose receptor (MR), the toll-like receptor (TLR) and the scavenger receptor (SR) $[108,109]$. MR-mediated phagocytosis results in a variety of downstream events, including the permeability of the lysosome, the generation of ROS, the activation of NF- $\mathrm{kB}$ and the release of proinflammatory cytokines, such as IL-1, IL-6, and TNF- $\alpha$ [110-113]. However, SR-mediated phagocytosis is not accompanied by proinflammatory cytokine secretion and NF- $\mathrm{kB}$ activation [108].

After particle internalisation, activated macrophages mediated carbon nanomaterial-induced pulmonary inflammation and fibrotic changes. In the early stage of CNT-induced inflammation (inhalation or intraperitoneal injection), macrophages are the major type of recruited inflammatory cells. After a single intratracheal instillation of carbon black nanoparticles at higher doses (i.e., 0.054 and $0.162 \mathrm{mg}$ ), the number of macrophages in bronchoalveolar lavage (BALF) decreased on the first day but elevated on the third day [114]. Frank et al. revealed that exposure to MWCNTs (4 mg/kg body weight) in mice via orotracheal aspiration caused a time-dependent neutrophil influx and proinflammatory mediator release (TNF- $\alpha$ and IL-6) in the BALF at indicated time points. Alveolar macrophages functioned as the major effector cells in CNT-triggered pulmonary inflammation through the MyD88 pathway. The underlying mechanism is presented in Fig. 3. The depletion of alveolar macrophages by liposomal clodronate (LC) pretreatment reduced CNT-induced inflammation in vivo, and further in vitro experiments identified the effector role of alveolar macrophages in inflammatory responses [115].

In the chronic phase after MWCNT exposure (inhalation or intratracheal instillation), macrophages remained in rat lungs as the main infiltrating cells [116]. Intratracheal instillation of SWCNTs (i.e., 0.04, 0.2 and $1 \mathrm{mg} / \mathrm{kg}$ ) led to increased numbers of macrophages in BALF in a dose-dependent manner from day 3 up to 3 months after exposure. Alveolar macrophage accumulation was observed in the lung sections at day 3 up to 6 months after instillation. Deposited SWCNTs in the lungs were phagocytosed by alveolar macrophages or macrophages in the interstitial tissues, which was related to inflammation and fibrotic changes [117]. Intratracheal instillation of MWCNTs $(4 \mathrm{mg} / \mathrm{kg})$ induced pulmonary interstitial fibrosis in rat lungs where the alveolar macrophages produced platelet-derived growth factors (PDGF)-AA, an important mediator of pro-fibrosis [118].

In one study, two different CNTs (long tangled and long rod-like CNTs) and asbestos were used for pharyngeal aspiration (10 $\mu \mathrm{g}$ or $40 \mu \mathrm{g}$ per mouse) in mice. Sixteen hours after exposure, rod-like CNTs and asbestos induced strong neutrophil influx into the lungs with increased proinflammatory cytokines and chemokines. IL- $1 \mathrm{R}^{-/-}$mice and antagonist-treated (etanercept and anakinra) mice presented attenuated inflammatory reactions, indicating the 


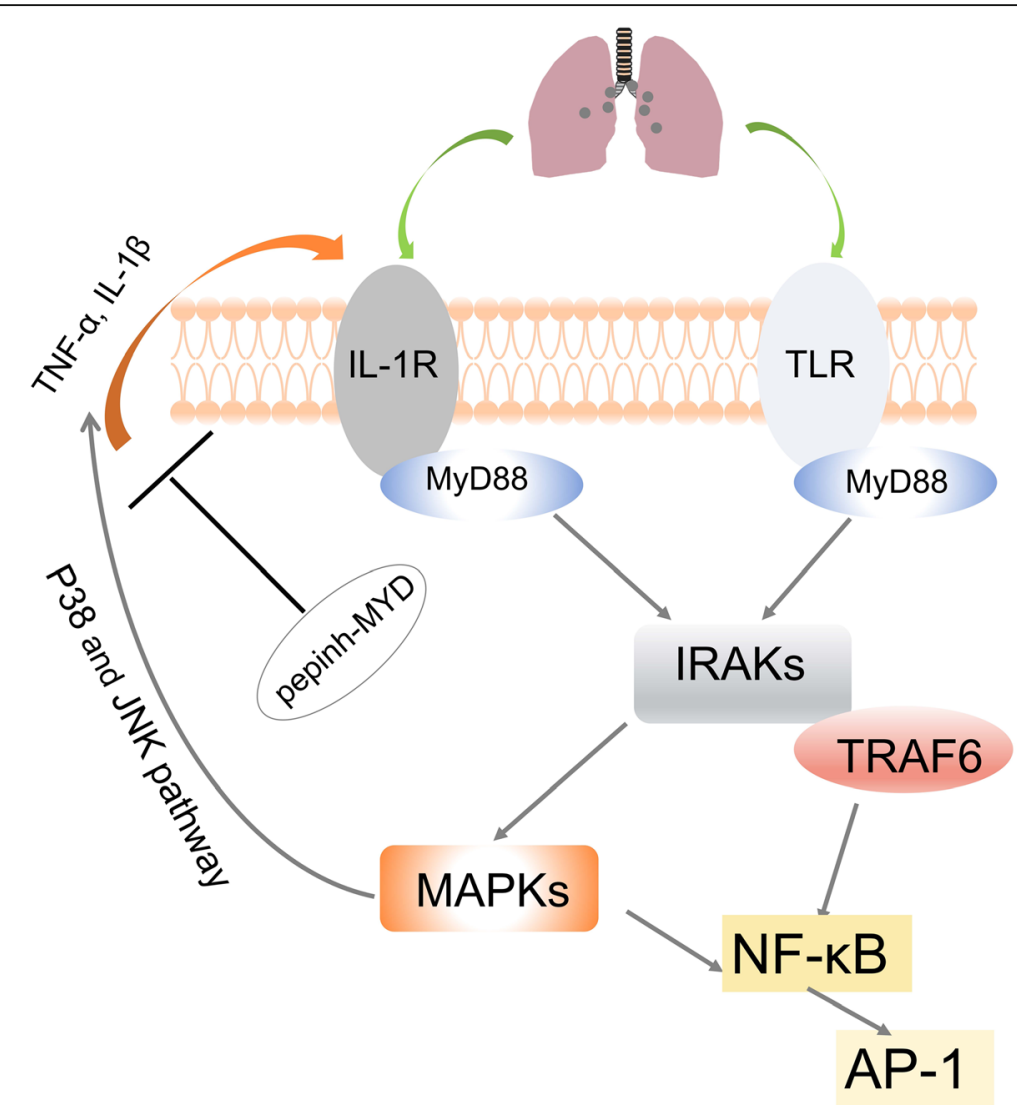

Fig. 3 MyD88 played a critical role in alveolar macrophage-mediated inflammatory response to CNTs. MyD88 mediated CNTs toxicity by linking IL-1R or TLR-dependent signaling and acted on downstream IRAKs and TRAFs, thus inducing proinflammatory NF-KB pathway. Also, MAPKs was involved in toxic response and MAPK inhibitors for p38 and JNK reduced levels of TNF- $a$ and IL-1 $\beta$. MyD88-specific inhibitory peptide blocked the production of TNF- $a$ and IL-1 $\beta$

important role of the IL-1R signaling pathway in the observed pulmonary inflammation [119]. Chronic exposure resulted in lung pathology such as hyperplasia and granulomatous lesions [120, 121]. MWCNTs (5 to $40 \mu \mathrm{g}$ ) via pharyngeal aspiration promoted rapid and prominent fibrosis formation remarkably near where the particles were deposited in the lungs and could also significantly increase TGF- $\beta 1$ and PDGF-A in the lungs. Pronounced infiltration of neutrophils and macrophages was observed alongside fibrosis [122].

Intratracheal instillation of SWCNTs $(0.3 \mu \mathrm{g}$ to $0.5 \mathrm{mg}$ per mouse) induced airway hyperreactivity (AHR) and airflow obstruction, mimicking obstructive airway disease. The underlying mechanism is presented in Fig. 4. Several proteins are upregulated, including cathepsin K, MMP 12, CCL2 and CCL3, and macrophage receptors such as Toll-like receptor 2 and macrophage scavenger receptor 1 . SWCNT-induced airway hyperreactivity can be attenuated by a cathepsin $\mathrm{K}$ inhibitor. The NF-KB pathway and downstream signals dominate the pathologic process and inflammatory responses. Pyrrolidine dithiocarbamate, an
NF- $\mathrm{KB}$ inhibitor, reduced the pathologic process as well as MMP12 and cathepsin K expression in animals [123].

In addition to direct effects, carbon nanomaterials enhanced airway allergic immune responses to allergens. After footpad injection and intranasal administration of carbon nanoparticles with an OVA booster, the levels of OVA-specific IgE and IgG1 rose significantly higher than they did after OVA alone. Intranasal exposure induced airway inflammation characterized by increased cell numbers (neutrophils, lymphocytes, and eosinophils) and cytokine levels (MCP-1 and TNF- $\alpha$ ) in BALF. Additionally, the total number of cells in the MLNs (mediastinal lymph nodes) was increased in the treated group [124]. With an OVA booster, pulmonary exposure to MWCNTs by repeated intratracheal administration aggravated airway inflammation (infiltration of immune cells and production of cytokines) and increased serum immunoglobulin levels (allergen-specific IgG1 and IgE) compared with allergen alone [125]. In the presence of carbon nanoparticles via pharyngeal aspiration $(2.5 \mathrm{mg} /$ $\mathrm{kg}$ body weight), exposure to an antigen induced 


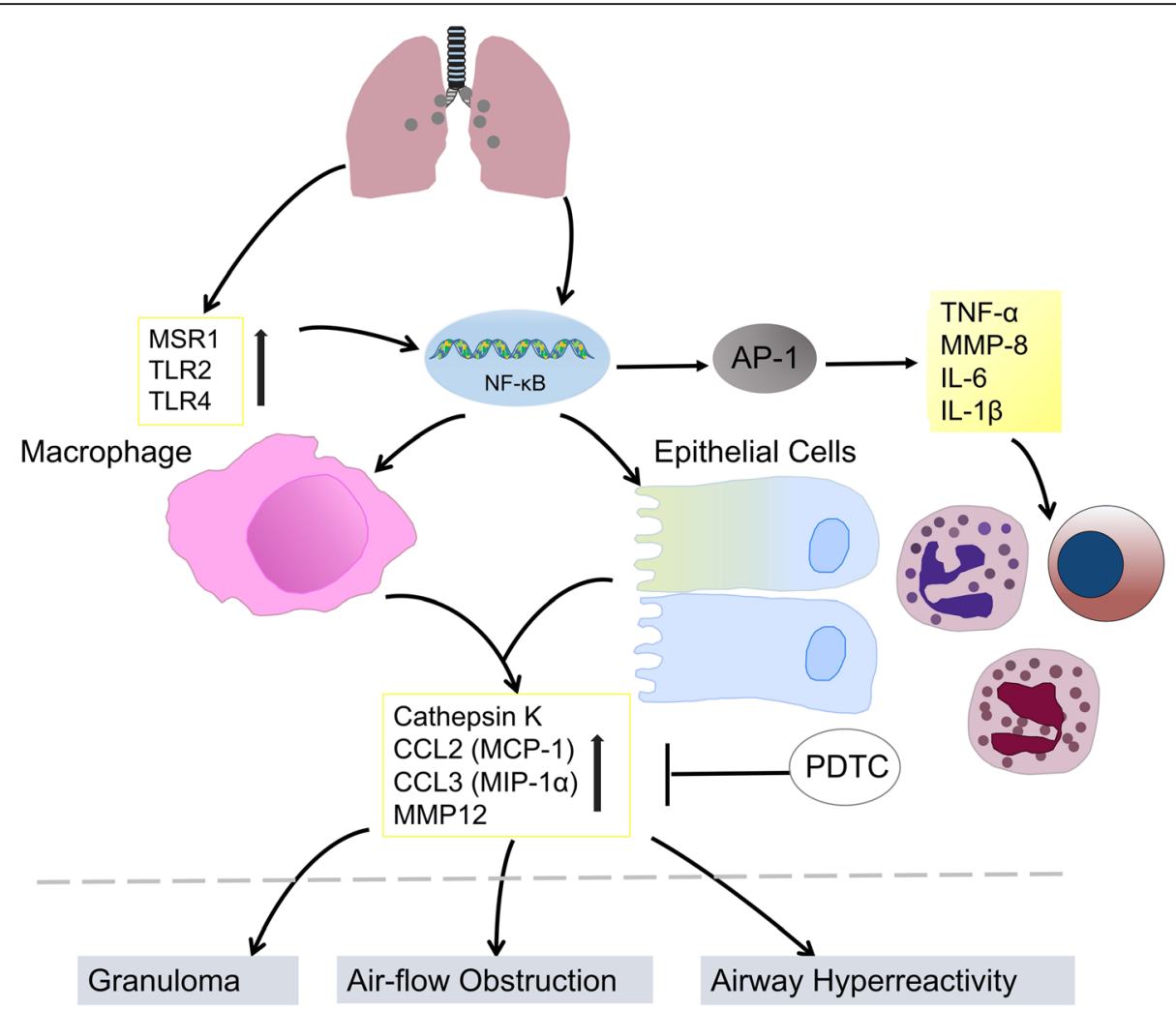

Fig. 4 SWCNTs induced lung injury. Inhalation of SWCNTs could up-regulate chemokines, proteinases and several macrophage receptors, also resulting in NF-kB-related inflammatory responses, which play roles in lung pathology including airway hyperreaction, airflow obstruction and granuloma. In vitro experiments indicated that the cell-cell interaction of bronchoalveolar macrophages with lung epithelial cells induced MMP12 and cathepsin K. Blocking NF-KB with PDTC could attenuate SWCNTs-induced chemokine and proteinase expression

increased allergic airway inflammation and specific TH2 response in the lymph nodes. The application of ectoine reduced these effects during sensitization. The results showed that exposure of the airways to carbonaceous nanoparticles exhibited adjuvant effects by aggravating the allergic immune response during the sensitization against allergens [126].

\section{Activation of other immune cells}

Airway epithelial cells Shortly after airway exposure via instillation $(20 \mu \mathrm{g})$, an acute inflammatory response was observed in BALF, characterized by prominent neutrophil accumulation and increased levels of neutrophil chemoattractants. As early as $3 \mathrm{~h}, 50 \%$ of AMs were loaded with black particle, and extracted AMs from the lungs presented no proinflammatory signature. In contrast, through gene expression analysis, alveolar epithelial type II cells were identified as the primary source of CXCL cytokines [127]. A mouse model of asthma was induced using house dust mites (HDM), and the mice were then exposed to MWCNTs by intranasal instillation. The results showed that exposure to multiwalled carbon nanotubes aggravated airway inflammation and induced the generation of epithelium-derived innate cytokines compared with exposure to HDM alone [128].

Mast cells In one study, two different types of CNTs (rigid rod-like and flexible tangled CNTs) were used by inhalation for $4 \mathrm{~h} /$ day for 4 consecutive days, mimicking one-week of occupational exposure. The results showed that rod-like CNTs caused allergic-like airway inflammation. Rod-shaped CNTs but not tangled CNTs, promoted the upregulation of innate immunity-relevant genes and cytokine/chemokine pathways after $4 \mathrm{~h}$ of exposure. Mast cell-deficient mice presented attenuated lung inflammation, suggesting the critical role of mast cells in allergic inflammation induced by rod-like CNTs [129]. Mast cells make responses to danger signals through various receptors, such as the IL-1-like receptor ST2, which is activated upon combining with its ligand IL-33 [130, 131]. In one study, the mice received a single dose of MWCNTs (4 $\mathrm{mg} / \mathrm{kg}$ body weight) by oropharyngeal aspiration. For the first time, the study confirmed that mast cells and the IL-33/ST2 axis mediated MWCNT-induced pulmonary and cardiovascular responses. he toxicological effects of MWCNTs were not observed in mast cell-deficient mice or in mice without response to IL-33 [132]. 
Lymphocyte Intratracheal instillation of MWCNTs (5, 20 , and $50 \mathrm{mg} / \mathrm{kg}$ body weight) increased proinflammatory cytokines in BALF and in blood, peaking at day 1 postexposure. The elevation of Th2-type cytokines was more pronounced than that of Th1-type cytokines. Additionally, the number of $B$ cells in the spleen and blood was considerably enhanced, indicating $B$ cell activation by Th2-type cytokines [133]. In another study, MWCNTs stimulated the proliferative response of $\mathrm{T}$ lymphocytes after intravenous injection (100 $\mu \mathrm{g} /$ mouse), and mRNA expression of proinflammatory macrophageproduced cytokines such as TNF- $\alpha$ and IL- 6 significantly increased. IFN- $\gamma$, a proinflammatory cytokine, was mainly produced by lymphocytes and the administration of MWCNTs induced immunized mice to release IFN- $\gamma$, TNF- $\alpha$ and IL-6, indicating the important adjuvant immune effect of MWCNTs. MWCNTs induced the release of proinflammatory cytokines by macrophages, which in turns stimulates $\mathrm{T}$ lymphocytes [134].

Systemic activation of immune cells There is evidence that local exposure (airway exposure or intraperitoneal injection) induces not only local adverse effects, but also systematic inflammatory responses. Pharyngeal aspiration of CNT (40 $\mu \mathrm{g}$ per mouse) caused an early increase in serum cytokines and inflammatory gene expression in serum. Eosinophils in blood and BALF consistently increased beyond $24 \mathrm{~h}$, and after 28 days, systemic markers of immune function were increased [34].

\section{Activation of the complement system}

After entering the bloodstream, CNTs may interact with the immune system, and the complement system is an integral part of the innate immune system, that is involved in defense against foreign pathogens and in the clearance of debris [135]. Complement activation leads to the production of the anaphylatoxins and chemoattractants C3a and C5a, which may cause anaphylaxis in sensitive individuals [136]. The C1 complex can initiate the activation of the classical complement pathway, triggering a cascade of proteolytic reactions. The $\mathrm{C} 1$ complex comprises two subunits: $\mathrm{C} 1 \mathrm{q}$ as the recognition protein and $\mathrm{C} 1 \mathrm{~s}-\mathrm{C} 1 \mathrm{r}-\mathrm{C} 1 \mathrm{r}-\mathrm{C} 1 \mathrm{~s}$ as the proenzyme tetrameric complex [137, 138]. One study observed that despite the organized binding of $\mathrm{C} 1 \mathrm{q}$ and $\mathrm{C} 1 \mathrm{~s}-\mathrm{C} 1 \mathrm{r}-\mathrm{C} 1 \mathrm{r}-\mathrm{C} 1 \mathrm{~s}$ on carbon nanotubes, no nanotubes induced the activation of the C1 complex [135]. In contrast, Salvador-Morales et al. reported that nonfunctionalized high-pressure carbon monoxide single-walled carbon nanotubes (HiPco SWNTs) and double-walled carbon nanotubes (DWNTs) could trigger the activation of the complement system [139].
PEGylation is widely used for surface modification of nanoparticles, increasing nanoparticle stabilization and prolonging circulation time in the bloodstream [140]. Surface PEGylation of carbon nanotubes makes the nanoparticles dispersible in aqueous solvents, which improves their utility in a variety of applications [141-144]. One study reported that PEGylated nanotubes induced elevation of SC5b-9, and in C1q-depleted serum, nanotubes mediated complement activation, indicating the independence of classical pathway. Intravenous administration of PEGylated nanotubes $(1.2 \mathrm{mg} / \mathrm{kg})$ in rats induced a remarkable increase in plasma thromboxane B2 levels, which suggested that nanotube initiated complement activation in vivo [145]. MWCNTs-PEG, despite differing PEG molecular weights, led to increases in serum levels of C4d [145, 146] and SC5b-9 [145] in a concentration-dependent manner, which is indicative of complement system activation in human serum. To shed light on the role of PEG surface engineering in complement activation, one extended study was performed with MWCNTs-PEG of different chain lengths. The results showed that all PEGylated nanotubes were capable of activating the complement system equally, independent of PEG loading length [147]. Albumin-coated SWCNTs were more water-soluble and activated C1q-mediated classical and alternative pathways differently. These findings provide insight into the utility of nanomaterial surface modification to increase innate immunocompatibility [146].

\section{Inducing immunosuppression}

There were reports that CNTs did not induce inflammatory responses as expected, but even caused immunosuppression. In one study of exposure of MWCNTs by inhalation $\left(0.3-5 \mathrm{mg} / \mathrm{m}^{3}, 6 \mathrm{~h} /\right.$ day) for 7 or 14 days, no inflammation or tissue damage was observed. However, MWCNT exposure induced immunosuppression, characterized by decreased NK cell function and T cell-dependent antibody response. Lung histopathology of exposed animals showed alveolar macrophages loaded with black particles, and particle-laden macrophages were also observed in bronchial alveolar lavage fluid [148]. MWCNT inhalation (0.3 or 1 $\mathrm{mg} / \mathrm{m}^{3}, 6 \mathrm{~h} /$ day) for 14 consecutive days induced compromised systemic immune function in mice, characterized by a decrease in antibody production in response to antigen challenge, but inhaled MWCNTs did not alter lymphocyte subpopulations. Ibuprofen partially rescued exposed animals from $\mathrm{T}$ cell-dependent antibody suppression, and cyclooxygenase-2 knockout mice were insusceptible to MWCNT-induced immunosuppression [149].

\section{Biodegradation of carbon nanoparticles by immune cells}

A comparative study was performed to evaluate the capacity of different peroxidases (HRP, MPO, LPO) to 
degrade SWCNTs, and the results from an in vitro model showed that three oxidants reacted with SWCNTs, causing their degradation [150]. Myeloperoxidase (MPO) and lipid peroxide (LPO) presented a higher capacity of degrading SWCNTs, attributed to the formation of hypohalous acid $(\mathrm{HOCl}$ and $\mathrm{HOBr}$, respectively) [151, 152]. MPO are produced by activated neutrophils; therefore, $\mathrm{MPO}$ and $\mathrm{HOCl}$ may be present at high concentrations at inflammatory sites, favoring the degradation of nanotubes [153]. Shvedova et al. (2012a) found that the clearance of SWCNTs from the lungs of exposed MPO knockout mice was remarkably reduced compared with clearance in wild-type animals, indicating the involvement of MPO in the biodegradation of SWCNTs in vivo [154]. It has been proposed that the biodegradation of carbon nanotubes by MPO might reduce pulmonary inflammation. show \$132\#?>inflammatory response. In contrast, the number of neutrophils and the levels of cytokines in BALF after pharyngeal aspiration of biodegraded nanotubes were indistinguishable from those in the control group. The findings indicated that inflammatory responses induced by carbon nanotubes were heavily dependent on the degree of biodegradation of particles in exposed individuals [73].

Eosinophil peroxidase (EPO), as a heme-containing haloperoxidase, is one major enzyme-generating oxidant in the human lung, notably at inflammatory sites and has 68\% sequence identity to MPO [155]. The superoxide-generating activity of eosinophils is robust due to the high expression of NADPH oxidase [156]. It was reported that CNT exposure via pharyngeal aspiration $(50 \mu \mathrm{g} /$ mouse $)$ could induce acute pulmonary eosinophilia and the subsequent release of EPO by eosinophils into inflammatory sites in the lungs [157]. Another study found that EPO released from eosinophils mediated the biodegradation of SWCNTs, which suggested that activated eosinophils played an important role in pulmonary responses to these materials [158].

\section{Potential factors influencing immunological effects in vivo}

\section{Physical properties of carbon nanomaterials}

Length Two types of SWCNTs, namely relatively thin bundles with short linear shapes (CNT-1) and thick bundles with long linear shapes (CNT-2), were prepared for in vivo tests in rats. The results showed that CNT-2 induced acute lung inflammation shortly after exposure, suggesting that SWCNT-induced pulmonary toxicity is closely associated with the length of particles [66]. CNTs reportedly elicit a length-dependent inflammatory response in the pleural cavity of mice. The authors addressed that macrophages were activated by long fibres via frustrated phagocytosis that stimulated a dramatic amplification of proinflammatory cytokines from mesothelial cells [159]. In another study, the results showed that peritoneal exposure to CNTs resulted in asbestos-like, lengthdependent inflammation and granuloma changes. Only the samples containing long fibres induced significant polymorphonuclear leukocyte (PMN) and protein exudation. Granuloma formation was observed on the peritoneal side of the diaphragm in mice after treatment with long fibres [160].

Size Two samples of MWCNTs with similar lengths but different diameters $(9.4 \mathrm{vs} 70 \mathrm{~nm})$ were intratracheally instilled in rats. The thinner MWCNTs induced greater LDH activity and infiltration of lymphocytes and neutrophils in BALF than the thicker MWCNTs [69]. Ultrafine particles are important contributing factors in the adverse health effects of particulate air pollution. One study compared the lung toxicity induced by ultrafine carbon black (ufCB) and carbon black particles with mean diameters 14.3 $\mathrm{nm}$ and $260.2 \mathrm{~nm}$, respectively. As a result, ufCB induced more neutrophil recruitment and epithelial injury than fine particles in rat lungs after instillation at an equal dose [161]. In another similar study, the toxic effects of ufCB (diameter $14 \mathrm{~nm}$ ) and $\mathrm{CB}$ particles (diameter $320 \mathrm{~nm}$ ) were tested. UfCB induced more prominent neutrophil recruitment and LDH activity in BALF than $\mathrm{CB}$ after $24 \mathrm{~h}$ of instillation [162]. Sonication is often used to deagglomerate carbon nanoparticles, and one study investigated the effect of sonication on toxic responses. Rats were exposed to carbon black aerosols with (group S) or without (group $\mathrm{N}$ ) sonication. Compared to group $\mathrm{N}$, group $S$ had a notable increase in the number of particles deposited in the lungs and in the amount of inflammation. No differences were observed in the levels of inflammatory cytokines or damage-indicating proteins between the two groups in the 3-day experiment, whereas 2-week exposure induced increased numbers of total cells, macrophages, and PMNs in group S [163].

Shape Two different types of CNTs (rigid rod-like and flexible tangled CNTs) were used by inhalation, mimicking one-week of occupational exposure, and the results showed that rod-like CNTs caused allergic-like airway inflammation. Rod-shaped CNTs but not tangled CNTs, promoted the upregulation of innate immunity-relevant genes and cytokine/chemokine pathways after 4-hour exposure [129].

Dispersion CNTs dispersed in BSA, but not in $\mathrm{NaCl}$ solution, remarkably accentuated inflammatory cell infiltration in BALF, and the number of CNT-loaded cells 
was also increased [164]. A recent report might provide a possible explanation. The study showed that CNTs presented improved dispersion in media containing FCS due to the physisorption between CNTs and the protein in the FCS-media through van der Waals forces. Similarly, BSA improved CNT dispersion without surface modification, providing new insights into the biocompatibility and toxic effects of nanoparticles [165].

Surface functionalization of nanomaterials MWCNTs and MWCNTs-COOH were tested in mice for pulmonary inflammation and injury biomarkers. The results showed that MWCNTs-COOH presented reduced bioactivity and pathogenicity. Additionally, activation of the NLRP3 inflammasome was found to be involved in MWCNTs- and MWCNTs-COOH-induced pulmonary pathogenicity [166]. Functionalized carbon nanotubes (f-CNTs) are more widely used than unmodified CNTs due to higher dispersion and outstanding physicochemical properties. In one study, several types of covalently functionalized multiwall carbon nanotubes (f-MWCNTs) were used in animals, including carboxylated $(\mathrm{COOH})$, polyethylene glycol (PEG), amine (NH2), sidewall amine (sw-NH2) and polyetherimide (PEI) modified MWCNTs. Compared to pristine MWCNTs, cationic PEI-MWCNTs induced obvious lung fibrosis, whereas reduced pulmonary fibrosis was observed in the group of MWCNT-COOH.These results indicated that surface charge might play an important role in f-MWCNT-induced lung damage [167]. Biochemical and cellular indicators of lung damage were evaluated after exposure to water-soluble tau-MWNTs, raw-MWNTs and positive control crystalline silicon dioxide particles. The findings showed that silicon dioxide particles induced heavier damage to lungs than CNTs and that tau-MWNTs produced slight, reversible pulmonary inflammation in mice. Tau-MWNTs are less toxic than insoluble raw MWNTs, suggesting that SWCNT-induced pulmonary toxicity is closely associated with the solubility of particles [168].

Metal impurities Nine different well-characterized MWCNT were examined in vivo, and they exhibited differential magnitudes of inflammatory and pathogenic potency. The authors pointed out that the outcome was closely related to nickel contamination on the particle surface, and the underlying mechanism might be that the Ni-contaminated particles induced NLRP3 activation followed by cytokine release, resulting in prolonged inflammation and lung pathology [169].

\section{Conclusions}

Due to their unique physicochemical properties, carbon nanomaterials are used for widespread applications ranging from industry to biomedicine. In parallel, carbon nanomaterial exposure has also raised concerns over health hazards associated with their properties [66]. At the beginning of research and development of any carbon nanomaterial, it is necessary to evaluate the potential toxic effects of the material and identify the physicochemical properties that are responsible for toxicity. Additionally, it is crucial to clarify the molecular mechanisms of carbon nanomaterial-induced cytotoxicity [42].

Here, we reviewed the cytotoxicities of carbon nanomaterials in cell culture-based assay systems; however, findings on the topic remain controversial. Some investigators have reported cytotoxic effects against various cell types. In contrast, several studies observed contradictory cytotoxicity results in the same materials and cell types. Despite progress in analytical techniques, assessing the cytotoxicity of carbon nanomaterials still poses considerable challenges. It is not yet understood which aspects of carbon nanomaterials, e.g., surface areas, mass concentrations, lengths, dispersibilities, metal impurities, a combination of these features, or some other factors, play a central role in cytotoxicity. Current toxicological studies have not truly revealed any new cellular toxicity mechanisms of carbon nanomaterials.

Lung epithelial cell lines, such as A549, and macrophage cell lines, such as NR8383, J774, and RAW264.7, are commonly chosen to evaluate the cytotoxicities of carbon nanomaterials. As a lung adenocarcinoma-derived cell line, A549 cells are endowed with cellular markers of type II pulmonary epithelium, serving as a useful in vitro model for studying the biological effects of particulate matter. Multiple types of macrophages are well-characterized cellular models because macrophages phagocytose particles, secrete specific cytokines, synthesize lysozyme and express Fc receptors. Cellular assays showed that carbon nanomaterials generally present more toxicity in macrophages than in other cell types, such as A549 cells, which is consistent with the nature of macrophages as professional phagocytes.

Discussions of toxicity point to poor dispersion of nanomaterials in aqueous media, which challenges the reproducibility of data acquired in toxicological assays [3]. The degree of dispersion of carbon nanomaterials impacts their in vitro and in vivo toxicity. Noncovalent functionalization with surfactants can disrupt bundles of CNTs, thus inducing greatly varied cellular responses. BSA, a water-soluble protein, can be absorbed on the CNT surface and provides excellent dispersing capability for CNTs. In previous studies, BSA, Pluronic F68 (a surfactant) and TWEEN 80 were used for dispersing CNTs in an aqueous environment; as a result, diminished toxic effects were observed [170]. It was reported that CNT-exposed endothelial cells did not exhibit significant acute toxicity in medium containing serum [3]. Similarly, 
studies on silica toxicity revealed that a synthetic surfactant protected alveolar macrophages in vitro against cell death and alleviated lung injury following silica exposure in vivo [171].

Catalytic metals are used during the manufacture of CNTs, and metallic impurities inevitably remain in CNTs. Numerous studies have proposed that residual catalytic metals induce oxidative stress, resulting in cell death. However, a meta-analysis of nanotoxicity studies showed that CNT-induced lung injury is not dominated by metallic impurities [66], and several studies identified the CNTs themselves rather than metal catalysts as the primary cause of cytotoxicity in macrophages [170].

Taurine-functionalized SWCNTs with greater water solubility presented less cytotoxicity against macrophages in some studies $[60,79]$. In contrast, other studies found the opposite results. For instance, it was reported that SWCNTs functionalized with carboxylic acid had higher toxicity than pristine SWCNTs in human endothelial cells [172]. The oxidation process reduces the length and straightens the shape of the tubes; thus, it was reported that oxidized MWCNTs induced stronger toxicity than pristine MWCNTs [102]. The difference may be attributed to the chemical and physicochemical parameters of functionalized nanomaterials, such as size, shape, and agglomeration.

In nanotoxicology studies, fluorescent probes are widely used to mark cell death, oxidant production or protein changes. Carbon nanoparticles with surface areas from 20 to $200 \mathrm{~m}^{2} / \mathrm{g}$ serve as universal sorbents of organic compounds in dispersing medium, including not only fluorescent dyes but also proteins, DNA and even salts that are used in toxicity assays. Monterio-Riviere et al. proposed that carbon nanoparticles might interfere with fluorescent assays via absorption or other methods [3]. Indeed, carbon nanomaterials have been found to interfere with assay components and read-out, causing inconsistent results concerning toxicity.

As the application of carbonaceous nanomaterials expands, the size of the exposed population continues to increase and some crucial issues should be addressed regarding their toxicity. Carbon nanomaterials present significantly different cytotoxicity depending on their physicochemical properties, including size, length, shape, and surface area. Additionally, most CNTs are complex mixtures containing multiple carbon forms and catalytic metal residues, which affect the biological cellular responses of exposed cells. Thus, when carbon nanomaterials are tested, it is necessary for researchers to characterize them in detail for the reliability, reproducibility and comparability of data acquired in toxicological assays. In terms of toxicity models, comprehensive experimental information is required to be provided, including the target cell types, dispersion methods, exposure dosage, administration route in vivo [3]. Carbon nanomaterials may present distinct toxic effects on macrophages in different viability assays, since interferences and disturbances are likely to occur. Great care should be taken when carrying out toxicity assays in the presence of fine carbon, and we note that multiple individual cellular bioassays can be performed simultaneously to confirm the findings. Based on comprehensive toxicological studies, better material characteristics are associated with less toxic effects. Differing from many other toxicants, carbon nanomaterials are mostly manufactured; thus, it is practicable for material scientists to modify specific material features, e.g., by removing metal impurities, applying surfactant coatings, or controlling the length of nanotubes to pave the way for possible design of less toxic materials.

It is now clear that the immune system can respond to CNTs and that the interactions are influenced by many factors. Additionally, different types of carbon nanoparticles present different immune compatibility. Physicochemical characteristics of the nanomaterials, such as their lengths, purities, solubilities and surface groups, significantly affect immune system responses. For example, "good" CNTs induce only slight inflammation and organismic damage and have relatively good biocompatibility in nanomedicine applications. Previous studies indicate that "good" CNTs should be short, functionalized, highly water-soluble and readily subjected to oxidative biodegradation. However, intentional or occupational exposure to "bad" CNTs might lead to harmful immune and nonimmune responses. In the future, carbon nanomaterials should be purposefully engineered for low toxicity. On the other hand, based on the immunostimulatory properties of CNTs, carbon nanomaterials could also be engineered for use in vaccines or any therapeutic protocol that requires activation of the immune system .

\section{Abbreviations \\ acid-MWCNTs: Acid-treated multiwalled carbon nanotubes; af-SWCNTs: Acid-functionalized single-walled carbon nanotubes; AMs: Alveolar macrophages; BALF: Bronchoalveolar lavage fluid; CB: Carbon black; CNTs: Carbon nanotubes; EPO: Eosinophil peroxidase; FCS: Fetal calf serum; f-MWCNTs: Functionalized multiwall carbon nanotubes; LDH: Lactate dehydrogenase; LMD: Lysosomal membrane destabilization; LPO: Lipid peroxide; MPO: Myeloperoxidase; MRI: Magnetic resonance imaging; MWCNTs: Multiwalled carbon nanotubes; MWCNTs-COOH: Carboxylated multiwalled carbon nanotubes; MWCNTs-PEG: PEG-functionalized multiwalled carbon nanotubes; NG: Nanographite; NPs: Nanoparticles; p-SWCNTs: Pristine single-walled carbon nanotubes; ROS: Reactive oxygen species; \\ SWCNHs: Single-walled carbon nanohorns; SWCNTs: Single-walled carbon nanotubes; tau-MWCNTs: Taurine-functionalized multiwalled carbon nanotubes}

\section{Acknowledgements}

All contributors who provided help during the research have been listed.

\section{Funding}

This work is supported by the National Natural Science Foundation of China (No. 81602492) and the National Key Research and Development Program of 
China (No. 2016YFA0201402). This research did not receive any specific grant from funding agencies in the public, commercial, or not-for-profit sectors.

\section{Availability of data and materials}

Not applicable.

\section{Authors' contributions}

$X W, Y W$. and XY. designed the study and contributed to all the sections; XZ. contributed to all of the sections except "the immunological effects of carbon-based nanomaterials" part; LS. helped with writing the manuscript.All authors read and approved the final manuscript

\section{Ethics approval and consent to participate}

Not applicable.

\section{Consent for publication}

Not applicable.

\section{Competing interests}

The authors declare that they have no competing interests.

\section{Publisher's Note}

Springer Nature remains neutral with regard to jurisdictional claims in published maps and institutional affiliations.

\section{Received: 8 November 2018 Accepted: 18 March 2019} Published online: 11 April 2019

\section{References}

1. Ray PC, Yu H, Fu PP. Toxicity and environmental risks of nanomaterials: challenges and future needs. J Environ Sci Health C Environ Carcinog Ecotoxicol Rev. 2009;27(1):1-35.

2. Hirsch A. The era of carbon allotropes. Nat Mater. 2010;9(11):868-71.

3. Hurt RH, Monthioux M, Kane A. Toxicology of carbon nanomaterials: Status, trends, and perspectives on the special issue. Carbon. 2006;44(6):1028-33.

4. Gorityala BK, Ma J, Wang X, Chen P, Liu XW. Carbohydrate functionalized carbon nanotubes and their applications. Chemical Society Reviews. 2010;39(8):2925.

5. Ge C, Meng L, Xu L, Bai R, Du J, Zhang L, et al. Acute pulmonary and moderate cardiovascular responses of spontaneously hypertensive rats after exposure to single-wall carbon nanotubes. Nanotoxicology. 2012;6(5):526-42.

6. Ge C, Du J, Zhao L, Wang L, Liu Y, Li D, et al. Binding of blood proteins to carbon nanotubes reduces cytotoxicity. Proc Natl Acad Sci U S A. 2011;108(41):16968-73.

7. Ge C, Lao F, Li W, Li Y, Chen C, Qiu Y, et al. Quantitative analysis of metal impurities in carbon nanotubes: efficacy of different pretreatment protocols for ICPMS spectroscopy. Anal Chem. 2008;80(24):9426-34.

8. Du J, Ge C, Liu Y, Bai R, Li D, Yang Y, et al. The interaction of serum proteins with carbon nanotubes depend on the physicochemical properties of nanotubes. J Nanosci Nanotechnol. 2011;11(11):10102-10.

9. Figarol A, Pourchez J, Boudard D, Forest V, Akono C, Tulliani JM, et al. In vitro toxicity of carbon nanotubes, nano-graphite and carbon black, similar impacts of acid functionalization. Toxicol in Vitro. 2015;30(1):476-85. https:// doi.org/10.1016/j.tiv.2015.09.014.

10. Long CM, Nascarella MA, Valberg PA. Carbon black vs. black carbon and other airborne materials containing elemental carbon: Physical and chemical distinctions. Environ Pollut. 2013;181(6):271-86.

11. Aschberger K, Johnston HJ, Stone V, Aitken RJ, Hankin SM, Peters SA, et al. Review of carbon nanotubes toxicity and exposure--appraisal of human health risk assessment based on open literature. Crit Rev Toxicol. 2010;40(9):759-90.

12. Panessawarren BJ, Warren JB, Wong SS, Misewich JA. Biological cellular response to carbon nanoparticle toxicity. J Phys Condens Matter. 2006; 18(33):S2185.

13. Zhu S, Xu G. Single-walled carbon nanohorns and their applications Nanoscale. 2010;2(12):2538-49.

14. Li Y, Liu Y, Fu Y, Wei T, Le GL, Gao G, et al. The triggering of apoptosis in macrophages by pristine graphene through the MAPK and TGF-beta signaling pathways. Biomaterials. 2012;33(2):402-11.

15. Velasco-Santos C, Martinez-Hernandez AL, Consultchi A, Rodriguez R, Castano VM. Naturally produced carbon nanotubes. Chem Phys Lett. 2003; 373(3-4):272-6 <Go to $|S|>$ ://WOS:000183016300007.
16. Warheit DB, Laurence BR, Reed KL, Roach DH, Reynolds GA, Webb TR. Comparative pulmonary toxicity assessment of single-wall carbon nanotubes in rats. Toxicol Sci. 2004;77(1):117-25. https://doi.org/10.1093/toxsci/kfg228.

17. Lam CW, James JT, McCluskey R, Hunter RL. Pulmonary toxicity of singlewall carbon nanotubes in mice 7 and 90 days after intratracheal instillation. Toxicol Sci. 2004;77(1):126-34. https://doi.org/10.1093/toxsci/kfg243.

18. Shvedova AA, Kisin ER, Mercer R, Murray AR, Johnson VJ, Potapovich Al, et al. Unusual inflammatory and fibrogenic pulmonary responses to single-walled carbon nanotubes in mice. Am J Physiol Lung Cell Mol Physiol. 2005;289(5): L698-708. https://doi.org/10.1152/ajplung.00084.2005.

19. Colvin VL. The potential environmental impact of engineered nanomaterials. Nat Biotechnol. 2003;21(10):1166-70. https://doi.org/10.1038/nbt875.

20. Oberdörster G, Oberdörster E, Oberdörster J. Nanotoxicology: An Emerging Discipline Evolving from Studies of Ultrafine Particles. Environ Health Perspect. 2005:113(7):823-39.

21. Donaldson $K$, Stone V, Tran CL, Kreyling W, Borm PJ. Nanotoxicology. Occup Environ Med. 2004;61(9):727-8. https://doi.org/10.1136/oem.2004.013243.

22. Donaldson K, Tran CL. Inflammation caused by particles and fibers. Inhal Toxicol. 2002;14(1):5-27. https://doi.org/10.1080/089583701753338613.

23. Nel A. Atmosphere. Air pollution-related illness: effects of particles. Science. 2005:308(5723):804-6. https://doi.org/10.1126/science.1108752.

24. Cui D, Tian F, Ozkan CS, Wang M, Gao H. Effect of single wall carbon nanotubes on human HEK293 cells. Toxicol Lett. 2005;155(1):73-85. https:// doi.org/10.1016/j.toxlet.2004.08.015.

25. Sayes CM, Gobin AM, Ausman KD, Mendez J, West JL, Colvin VL. Nano-C60 cytotoxicity is due to lipid peroxidation. Biomaterials. 2005;26(36):7587-95. https://doi.org/10.1016/j.biomaterials.2005.05.027.

26. Pulskamp K, Diabate S, Krug HF. Carbon nanotubes show no sign of acute toxicity but induce intracellular reactive oxygen species in dependence on contaminants. Toxicology letters. 2007;168(1):58-74. https://doi.org/10.1016/ j.toxlet.2006.11.001.

27. Meng J, Li X, Wang C, Guo H, Liu J, Xu H. Carbon nanotubes activate macrophages into a M1/M2 mixed status: recruiting naïve macrophages and supporting angiogenesis. Acs Appl Mater Interfaces. 2015;7(5):3180.

28. Gulati P. Janeway's Immunobiology, 7th Edition by Kenneth Murphy, Paul Travers, and Mark Walport. Biochem Mol Biol Educ. 2010:37(2):134.

29. Dumortier $\mathrm{H}$. When carbon nanotubes encounter the immune system: desirable and undesirable effects. Adv Drug Deliv Rev. 2013:65(15):2120-6. https://doi.org/10.1016/j.addr.2013.09.005.

30. Oberdörster G, Sharp Z, Atudorei V, Elder A, Gelein R, Kreyling W, et al. Translocation of Inhaled Ultrafine Particles to the Brain. Inhal Toxicol. 2004; 16(6-7):437

31. Moss OR, Wong VA. When nanoparticles get in the way: impact of projected area on in vivo and in vitro macrophage function. Inhal Toxicol. 2006:18(10):711-6. https://doi.org/10.1080/08958370600747770.

32. Koike $\mathrm{E}$, Kobayashi T. Chemical and biological oxidative effects of carbon black nanoparticles. Chemosphere. 2006;65(6):946-51. https://doi.org/10. 1016/j.chemosphere.2006.03.078.

33. Ema M, Gamo M, Honda K. A review of toxicity studies of single-walled carbon nanotubes in laboratory animals. Regul Toxicol Pharmacol. 2016;74 42-63.

34. Erdely A, Liston A, Salmenmuniz R, Hulderman T, Young SH, Zeidlererdely PC, et al. Identification of systemic markers from a pulmonary carbon nanotube exposure. J Occup Environ Med. 2011;53(6 Suppl):80-6.

35. Yang ST, Wang X, Jia G, Gu Y, Wang T, Nie H, et al. Long-term accumulation and low toxicity of single-walled carbon nanotubes in intravenously exposed mice. Toxicol Lett. 2012;181(3):182-9.

36. Erdely A, Hulderman T, Salmen R, Liston A, Zeidler-Erdely PC, SchweglerBerry $D$, et al. Cross-talk between lung and systemic circulation during carbon nanotube respiratory exposure. Potential biomarkers. Nano lett. 2009;9(1):36-43. https://doi.org/10.1021/nl801828z.

37. Yang S-T, Guo W, Lin $Y$, Deng $X-Y$, Wang H-F, Sun $H$, et al. Biodistribution of Pristine Single-Walled Carbon Nanotubes In Vivo. J Phys Chem C. 2007; 111(48):17761-4.

38. Dobrovolskaia MA, Mcneil SE. Immunological properties of engineered nanomaterials. Nature nanotechnology. 2007:2(8):469-78.

39. Orecchioni M, Bedognetti D, Sgarrella F, Marincola FM, Bianco A, Delogu LG. Impact of carbon nanotubes and graphene on immune cells. J Transl Med. 2014;12(1):138 12,1(2014-05-21)

40. Wan B, Wang ZX, Lv QY, Dong PX, Zhao LX, Yang Y, et al. Single-walled carbon nanotubes and graphene oxides induce autophagosome accumulation and 
lysosome impairment in primarily cultured murine peritoneal macrophages. Toxicol Lett. 2013;221(2):118-27. https://doi.org/10.1016/j.toxlet.2013.06.208.

41. Dong PX, Bin W, Wang ZX, Guo LH, Yang Y, Zhao L. Exposure of singlewalled carbon nanotubes impairs the functions of primarily cultured murine peritoneal macrophages. Nanotoxicology. 2013;7(5):1028-42.

42. Van BD, Wilhelmi V, Boots AW, Hullmann M, Kuhlbusch TA, Bast A, et al. Apoptotic, inflammatory, and fibrogenic effects of two different types of multiwalled carbon nanotubes in mouse lung. Arch Toxicol. 2014;88(9):1725-37.

43. Wang X, Guo J, Chen T, Nie H, Wang H, Zang J, et al. Multi-walled carbon nanotubes induce apoptosis via mitochondrial pathway and scavenger receptor. Toxicol In Vitro. 2012;26(6):799-806

44. Palomäki J, Karisola P, Pylkkänen L, Savolainen K, Alenius H. Engineered nanomaterials cause cytotoxicity and activation on mouse antigen presenting cells. Toxicology. 2010;267(3):125-31.

45. Jia G, Wang H, Yan L, Wang X, Pei R, Yan T, et al. Cytotoxicity of carbon nanomaterials: single-wall nanotube, multi-wall nanotube, and fullerene. Environ Sci Technol. 2005;39(5):1378-83.

46. Fiorito S, Serafino A, Andreola F, Bernier P. Effects of fullerenes and singlewall carbon nanotubes on murine and human macrophages. Carbon. 2006: 44(6):1100-5.

47. Reisetter AC, Stebounova LV, Baltrusaitis J, Powers L, Gupta A, Grassian VH, et al. Induction of inflammasome-dependent pyroptosis by carbon black nanoparticles. J Biol Chem. 2011;286(24):21844-52. https://doi.org/10.1074/ jbc.M111.238519.

48. Mu Q, Yang L, Davis JC, Vankayala R, Hwang KC, Zhao J, et al. Biocompatibility of polymer grafted core/shell iron/carbon nanoparticles. Biomaterials. 2010;31(19):5083-90.

49. Liu Y, Li W, Lao F, Liu Y, Wang L, Bai R, et al. Intracellular dynamics of cationic and anionic polystyrene nanoparticles without direct interaction with mitotic spindle and chromosomes. Biomaterials. 2011:32(32):8291-303.

50. Zhao $Y$, Xing G, Chai Z. Nanotoxicology: Are carbon nanotubes safe? Nat Nanotechnol. 2008:3(4):191-2

51. Tahara $Y$, Nakamura M, Yang M, Zhang M, lijima S, Yudasaka M. Lysosomal membrane destabilization induced by high accumulation of single-walled carbon nanohorns in murine macrophage RAW264.7. Biomaterials. 2012; 33(9):2762-9.

52. Sohaebuddin SK, Thevenot PT, Baker D, Eaton JW, Tang L. Nanomaterial cytotoxicity is composition, size, and cell type dependent. Part Fibre Toxicol. 2010;7(1):22

53. Kang S, Kim JE, Kim D, Chang GW, Pikhitsa PV, Cho MH, et al. Comparison of cellular toxicity between multi-walled carbon nanotubes and onion-like shell-shaped carbon nanoparticles. J Nanopart Res. 2015;17(9):1-11.

54. Shvedova AA, Castranova V, Kisin ER, Schwegler-Berry D, Murray AR, Gandelsman VZ, et al. Exposure to Carbon Nanotube Material: Assessment of Nanotube Cytotoxicity using Human Keratinocyte Cells. 2003.

55. Pacurari M, Yin XJ, Zhao J, Ding M, Leonard SS, Schwegler-Berry D, et al. Raw Single-Wall Carbon Nanotubes Induce Oxidative Stress and Activate MAPKs, AP-1, NF-kB, and Akt in Normal and Malignant Human Mesothelial Cells. Environ Health Perspect. 2008;116(9):1211-7. https://doi.org/10.1289/ ehp.10924.

56. Herzog E, Byrne HJ, Davoren M, Casey A, Duschl A, Oostingh GJ. Dispersion medium modulates oxidative stress response of human lung epithelial cells upon exposure to carbon nanomaterial samples. Toxicol Appl Pharmacol. 2009;236(3):276

57. Chen B, Liu Y, Song WM, Hayashi Y, Ding XC, Li WH. In vitro evaluation of cytotoxicity and oxidative stress induced by multiwalled carbon nanotubes in murine RAW 264.7 macrophages and human A549 lung cells. Biomed Environ Sci. 2011;24(6):593-601.

58. Yang M, Zhang M, Tahara Y, Chechetka S, Miyako E, lijima S, et al. Lysosomal membrane permeabilization: carbon nanohorn-induced reactive oxygen species generation and toxicity by this neglected mechanism. Toxicol Appl Pharmacol. 2014;280(1):117-26

59. Park EJ, Zahari NEM, Kang MS, Sang JL, Lee K, Lee BS, et al. Toxic response of HIPCO single-walled carbon nanotubes in mice and RAW264.7 macrophage cells. Toxicol lett. 2014;229(1):167-77.

60. Chen T, Zang J, Wang H, Nie H, Wang X, Shen Z, et al. Water-soluble taurinefunctionalized multi-walled carbon nanotubes induce less damage to mitochondria of RAW 264.7 cells. J Nanosci Nanotechnol. 2012;12(10):8008.

61. Cheng C, Müller KH, Koziol KK, Skepper JN, Midgley PA, Welland ME, et al. Toxicity and imaging of multi-walled carbon nanotubes in human macrophage cells. Biomaterials. 2009;30(25):4152-60.
62. Porter AE, Gass M, Bendall JS, Muller K, Goode A, Skepper JN, et al. Uptake of Noncytotoxic Acid-Treated Single-Walled Carbon Nanotubes into the Cytoplasm of Human Macrophage Cells. Acs Nano. 2009;3(6):1485.

63. Boyles MS, Young L, Brown DM, Maccalman L, Cowie H, Moisala A, et al. Multi-walled carbon nanotube induced frustrated phagocytosis, cytotoxicity and pro-inflammatory conditions in macrophages are length dependent and greater than that of asbestos. Toxicol In Vitro. 2015;29(7):1513.

64. Sweeney S, Grandolfo D, Ruenraroengsak P, Tetley TD. Functional consequences for primary human alveolar macrophages following treatment with long, but not short, multiwalled carbon nanotubes. Int J Nanomedicine. 2014;10:3115-29.

65. Sato Y, Yokoyama A, Shibata K, Akimoto Y, Ogino S, Nodasaka Y, et al. Influence of length on cytotoxicity of multi-walled carbon nanotubes against human acute monocytic leukemia cell line THP-1 in vitro and subcutaneous tissue of rats in vivo. Mol BioSyst. 2005;1(2):176-82. https:// doi.org/10.1039/b502429c.

66. Fujita K, Fukuda M, Endoh S, Maru J, Kato H, Nakamura A, et al. Size effects of single-walled carbon nanotubes on in vivo and in vitro pulmonary toxicity. Inhal Toxicol. 2015:27(4):207-23.

67. Magrez A, Kasas S, Salicio V, Pasquier N, Seo JW, Celio M, et al. Cellular toxicity of carbon-based nanomaterials. Nano Lett. 2006;6(6):1121-5.

68. Hirotaka N, Yasumasa O, Shan Hwu C, Nobuaki M, Yoriko Y, Shinya A, et al. Diameter and rigidity of multiwalled carbon nanotubes are critical factors in mesothelial injury and carcinogenesis. Proc Natl Acad Sci U S A. 2011; 108(49):19467-8.

69. Fenoglio I, Aldieri E, Gazzano E, Cesano F, Colonna M, Scarano D, et al. Thickness of multiwalled carbon nanotubes affects their lung toxicity. Chem Res Toxicol. 2012;25(1):74-82. https://doi.org/10.1021/tx200255h.

70. Kang S, Kim JE, Kim D, Woo CG, Pikhitsa PV, Cho MH, et al. Comparison of cellular toxicity between multi-walled carbon nanotubes and onion-like shell-shaped carbon nanoparticles. Journal of Nanoparticle Research. 2015; 17(9):378

71. Jiang $Y$, Zhang $H$, Wang $Y$, Chen M, Ye S, Hou Z, et al. Modulation of apoptotic pathways of macrophages by surface-functionalized multi-walled carbon nanotubes. PLoS One. 2013;8(6):1243-6.

72. Allen BL, Kotchey GP, Chen Y, Yanamala NV, Klein-Seetharaman J, Kagan VE, et al. Mechanistic investigations of horseradish peroxidase-catalyzed degradation of single-walled carbon nanotubes. J Am Chem Soc. 2009; 131(47):17194-205. https://doi.org/10.1021/ja9083623.

73. Kagan VE, Konduru NV, Feng W, Allen BL, Conroy J, Volkov Y, et al. Carbon nanotubes degraded by neutrophil myeloperoxidase induce less pulmonary inflammation. Nat Nanotechnol. 2010;5(5):354-9. https://doi.org/10.1038/ nnano.2010.44.

74. Allen BL, Kichambare PD, Gou P, Vlasova II, Kapralov AA, Konduru N, et al. Biodegradation of single-walled carbon nanotubes through enzymatic catalysis. Nano lett. 2008;8(11):3899-903. https://doi.org/10.1021/nl802315h.

75. Russier J, Menard-Moyon C, Venturelli E, Gravel E, Marcolongo G, Meneghetti $M$, et al. Oxidative biodegradation of single- and multi-walled carbon nanotubes. Nanoscale. 2011;3(3):893-6. https://doi.org/10.1039/c0nr00779j.

76. Sweeney S, Hu S, Ruenraroengsak P, Chen S, Gow A, Schwander S, et al. Carboxylation of multiwalled carbon nanotubes reduces their toxicity in primary human alveolar macrophages. Environ Sci Nano. 2016;3(6):1340-50.

77. Montes-Fonseca SL, Sánchez-Ramírez B, Luna-Velasco A, Arzate-Quintana C, Silva-Cazares MB, González HC, et al. Cytotoxicity of protein-carbon nanotubes on $\mathbf{J 7 7 4}$ macrophages is a functionalization grade-dependent effect. Biomed Res Int. 2014:2015:796456.

78. Montes-Fonseca SL, Orrantia-Borunda E, Aguilar-Elguezabal A, González HC, Talamás-Rohana P, Sánchez-Ramírez B. Cytotoxicity of functionalized carbon nanotubes in J774A macrophages. New Biotechnology. 2012:29(6):S203-S.

79. Sayes CM, Liang F, Hudson JL, Mendez J, Guo W, Beach JM, et al. Functionalization density dependence of single-walled carbon nanotubes cytotoxicity in vitro. Toxicol Lett. 2006;161(2):135-42.

80. Nimmagadda A, Thurston K, Nollert MU, McFetridge PS. Chemical modification of SWNT alters in vitro cell-SWNT interactions. J Biomed Mater Res A. 2006;76(3):614-25. https://doi.org/10.1002/jbm.a.30577.

81. Bottini M, Bruckner S, Nika K, Bottini N, Bellucci S, Magrini A, et al. Multiwalled carbon nanotubes induce T lymphocyte apoptosis. Toxicol Lett. 2006;160(2):121-6. https://doi.org/10.1016/j.toxlet.2005.06.020.

82. Bladh K, Falk LKL, Rohmund F. On the iron-catalysed growth of singlewalled carbon nanotubes and encapsulated metal particles in the gas phase. Applied Physics A. 2000;70(3):317-22 
83. Gorelik OP, Nikolaev P, Arepalli S. NASA/CR-2000-208926 Purification Procedures for Single-Wall Carbon Nanotubes; 2000.

84. Kagan VE, Tyurina YY, Tyurin VA, Konduru NV, Potapovich Al, Osipov AN, et al. Direct and indirect effects of single walled carbon nanotubes on RAW 264.7 macrophages: role of iron. Toxicol Lett. 2006;165(1):88-100.

85. Moolgavkar SH, Brown RC, Turim J. Biopersistence, fiber length, and cancer risk assessment for inhaled fibers. Inhal Toxicol. 2001;13(9):755-72.

86. Andersen AJ, Wibroe PP, Moghimi SM. Perspectives on carbon nanotubemediated adverse immune effects. Adv Drug Deliv Rev. 2012;64(15):1700-5. https://doi.org/10.1016/j.addr.2012.05.005.

87. Kam NWS, Connell M, Wisdom JA, Dai H. Carbon nanotubes as multifunctional biological transporters and near-infrared agents for selective cancer cell destruction. Proc Natl Acad Sci U S A. 2005;102(33):11600. https://doi.org/10.1073/pnas.0502680102 http://www.pnas.org/content/102/ 33/11600.abstract

88. Konduru NV, Tyurina YY, Weihong F, Basova LV, Belikova NA, Hülya B, et al. Phosphatidylserine targets single-walled carbon nanotubes to professional phagocytes in vitro and in vivo. Plos One. 2009;4(2):e4398.

89. Kagan VE, Tyurina YY, Tyurin VA, Konduru NV, Potapovich Al, Osipov AN, et al. Direct and indirect effects of single walled carbon nanotubes on RAW 264.7 macrophages: role of iron. Toxicol lett. 2006;165(1):88-100. https://doi. org/10.1016/j.toxlet.2006.02.001.

90. Kam NW, Dai H. Carbon nanotubes as intracellular protein transporters: generality and biological functionality. J Am Chem Soc. 2005;127(16): 6021-6. https://doi.org/10.1021/ja050062v

91. Klumpp C, Kostarelos K, Prato M, Bianco A. Functionalized carbon nanotubes as emerging nanovectors for the delivery of therapeutics. Biochim Biophys Acta. 2006;1758(3):404-12. https://doi.org/10.1016/j. bbamem.2005.10.008.

92. Kostarelos K, Lacerda L, Pastorin G, Wu W, Wieckowski S, Luangsivilay J, et al. Cellular uptake of functionalized carbon nanotubes is independent of functional group and cell type. Nat Nanotechnol. 2007;2(2):108-13. https:// doi.org/10.1038/nnano.2006.209.

93. Daleke DL. Regulation of transbilayer plasma membrane phospholipid asymmetry. J Lipid Res. 2003;44(2):233-42. https://doi.org/10.1194/jlr.R200019-JLR200.

94. Thoo L, Fahmi MZ, Zulkipli IN, Keasberry N, Idris A. Interaction and cellular uptake of surface-modified carbon dot nanoparticles by J774.1 macrophages. Cent Eur J Immunol. 2017;42(3):324-30. https://doi.org/10 5114/ceji.2017.70978 https://www.ncbi.nlm.nih.gov/pubmed/29204100 https://www.ncbi.nlm.nih.gov/pmc/PMC5708216/.

95. Witasp E, Shvedova AA, Kagan VE, Fadeel B. Single-walled carbon nanotubes impair human macrophage engulfment of apoptotic cell corpses. Inhalation Toxicology. 2009;21(s1):131-6.

96. Sweeney S, Grandolfo D, Ruenraroengsak P, Tetley TD. Functional consequences for primary human alveolar macrophages following treatment with long, but not short, multiwalled carbon nanotubes. Int J Nanomedicine. 2015;10:3115-29. https://doi.org/10.2147/ijn.s77867.

97. Zhang T, Tang M, Kong L, Li H, Zhang T, Zhang S, et al. Comparison of cytotoxic and inflammatory responses of pristine and functionalized multiwalled carbon nanotubes in RAW 264.7 mouse macrophages. J Hazard Mater. 2012;219(220):203-12. https://doi.org/10.1016/j.jhazmat.2012.03.079.

98. Palomaki J, Valimaki E, Sund J, Vippola M, Clausen PA, Jensen KA, et al. Long, needle-like carbon nanotubes and asbestos activate the NLRP3 inflammasome through a similar mechanism. ACS nano. 2011;5(9):6861-70. https://doi.org/10.1021/nn200595c

99. Lucia Gemma D, Enrica V, Roberto M, Gérard Aimé P, Ciriaco C, Roberto M, et al. Ex vivo impact of functionalized carbon nanotubes on human immune cells. Nanomedicine. 2012;7(2):231-43.

100. Zhao $S$, Zhe $L$, Jie M, Jie M, Jinhong $D$, Sishen $X$, et al. Carbon nanotubes enhance cytotoxicity mediated by human lymphocytes in vitro. Plos One. 2011;6(6):e21073

101. J-c Z, X-y J, C-I L, Shen S-g, Wang S-x, Sun J. Effect of single-walled carbon nanotubes on primary immune cells in vitro. Frontiers of Materials Science in China. 2008;2(2):228-32.

102. Bottini M, Bruckner S, Nika K, Bottini N, Bellucci S, Magrini A, et al. Multiwalled carbon nanotubes induce T lymphocyte apoptosis. Toxicol lett. 2006; 160(2):121-6.

103. Dumortier H, Lacotte S, Pastorin G, Marega R, Wu W, Bonifazi D, et al. Functionalized carbon nanotubes are non-cytotoxic and preserve the functionality of primary immune cells. Nano lett. 2006;6(7):1522-8. https:// doi.org/10.1021/nl061160x.
104. Yu JS, Liu G, Ying H, Yong WH, Black KL, Wheeler CJ. Vaccination with tumor lysate-pulsed dendritic cells elicits antigen-specific, cytotoxic T-cells in patients with malignant glioma. Cancer Res. 2004;64(14):4973-9. https://doi. org/10.1158/0008-5472.can-03-3505.

105. Reichardt VL, Brossart PL. Dendritic cells in vaccination therapies of human malignant disease. Blood Rev. 2004;18(4):235-43.

106. Sun Z, Wang W, Meng J, Chen S, Xu H, Yang XD. Multi-walled carbon nanotubes conjugated to tumor protein enhance the uptake of tumor antigens by human dendritic cells in vitro. Cell Res. 2010;20(10):1170-3. https://doi.org/10.1038/cr.2010.133.

107. Yang M, Flavin K, Kopf I, Radics G, Hearnden CH, McManus GJ, et al. Functionalization of carbon nanoparticles modulates inflammatory cell recruitment and NLRP3 inflammasome activation. Small. 2013;9(24):4194206. https://doi.org/10.1002/smll.201300481s.

108. Aderem A, Underhill DM. Mechanisms of phagocytosis in macrophages. Annu Rev Immunol. 1999;17:593-623. https://doi.org/10.1146/annurev. immunol.17.1.593.

109. Lorenzo S, González-Fernández A. Handbook of Immunological properties of Engineered nanomaterials. Singapore: World scientific; 2013. p.517-545.

110. Fraser IP, Koziel H, Ezekowitz RA. The serum mannose-binding protein and the macrophage mannose receptor are pattern recognition molecules that link innate and adaptive immunity. Semin Immunol. 1998;10(5):363-72.

111. Zhang J, Zhu J, Imrich A, Cushion M, Kinane TB, Koziel H. Pneumocystis activates human alveolar macrophage NF-kappaB signaling through mannose receptors. Infect Immun. 2004;72(6):3147.

112. East $L$, Isacke $C M$. The mannose receptor family. Biochim Biophys Acta. 2002;1572(2):364-86.

113. Stahl PD, Ezekowitz RA. The mannose receptor is a pattern recognition receptor involved in host defense. Curr Opin Immunol. 1998;10(1):50.

114. Bourdon JA, Saber AT, Jacobsen NR, Jensen KA, Madsen AM, Lamson JS, et al. Carbon black nanoparticle instillation induces sustained inflammation and genotoxicity in mouse lung and liver. Part Fibre Toxicol. 2012;9:5. https://doi.org/10.1186/1743-8977-9-5.

115. Frank EA, Birch ME, Yadav JS. MyD88 mediates in vivo effector functions of alveolar macrophages in acute lung inflammatory responses to carbon nanotube exposure. Toxicol Appl Pharmacol. 2015;288(3):322-9. https://doi. org/10.1016/j.taap.2015.08.004.

116. Yasuo M, Masami H, Akira O, Takako O, Toshihiko M, Motoi T, et al. Pulmonary toxicity of well-dispersed multi-wall carbon nanotubes following inhalation and intratracheal instillation. Nanotoxicology. 2012;6(6):587-99.

117. Kobayashi N, Naya M, Mizuno K, Yamamoto K, Ema M, Nakanishi J. Pulmonary and systemic responses of highly pure and well-dispersed single-wall carbon nanotubes after intratracheal instillation in rats. Inhal Toxicol. 2011;23(13):814-28. https://doi.org/10.3109/08958378.2011.614968.

118. Cesta MF, Dg RRJ, Masinde T, Hurlburt G, Taylor AJ, Bonner JC. Bacterial lipopolysaccharide enhances PDGF signaling and pulmonary fibrosis in rats exposed to carbon nanotubes. Am J Respir Cell Mol Biol. 2010;43(2):142-51.

119. Rydman EM, Ilves M, Vanhala E, Vippola M, Lehto M, Kinaret PA, et al. A Single Aspiration of Rod-like Carbon Nanotubes Induces Asbestos-like Pulmonary Inflammation Mediated in Part by the IL-1 Receptor. Toxicol Sci. 2015;147(1):140.

120. Mercer RR, Hubbs AF, Scabilloni JF, Wang L, Battelli LA, Friend S, et al. Pulmonary fibrotic response to aspiration of multi-walled carbon nanotubes. Part Fibre Toxicol. 2011:8:21. https://doi.org/10.1186/1743-8977-8-21.

121. Wang X, Katwa P, Podila R, Chen P, Ke PC, Rao AM, et al. Multi-walled carbon nanotube instillation impairs pulmonary function in C57BL/6 mice. Part Fibre Toxicol. 2011;8(1):24

122. Dong J, Porter DW, Batteli LA, Wolfarth MG, Richardson DL, Ma Q. Pathologic and molecular profiling of rapid-onset fibrosis and inflammation induced by multi-walled carbon nanotubes. Arch Toxicol. 2015;89(4):621-33.

123. Hsieh WY, Chou CC, Ho CC, Yu SL, Chen HY, Chou HY, et al. Single-walled carbon nanotubes induce airway hyperreactivity and parenchymal injury in mice. Am J Respir Cell Mol Biol. 2012;46(2):257-67.

124. Nygaard UC, Hansen JS, Samuelsen M, Alberg T, Marioara CD, Løvik M. Single-walled and multi-walled carbon nanotubes promote allergic immune responses in mice. Toxicol Sci. 2009;109(109):113-23.

125. Inoue $K$, Koike E, Yanagisawa R, Hirano S, Nishikawa M, Takano H. Effects of multi-walled carbon nanotubes on a murine allergic airway inflammation model. Toxicol Appl Pharmacol. 2009;237(3):306-16. https://doi.org/10.1016/ j.taap.2009.04.003

126. Kroker M, Sydlik U, Autengruber A, Cavelius C, Weighardt H, Kraegeloh A, et al. Preventing carbon nanoparticle-induced lung inflammation reduces 
antigen-specific sensitization and subsequent allergic reactions in a mouse model. Part Fibre Toxicol. 2015;12(1):20.

127. Chen S, Yin R, Mutze K, Yu Y, Takenaka S, Konigshoff M, et al. No involvement of alveolar macrophages in the initiation of carbon nanoparticle induced acute lung inflammation in mice. Part Fibre Toxicol. 2016;13(1):33. https://doi.org/10.1186/s12989-016-0144-6.

128. Ronzani C, Casset A, Pons F. Exposure to multi-walled carbon nanotubes results in aggravation of airway inflammation and remodeling and in increased production of epithelium-derived innate cytokines in a mouse model of asthma. Arch Toxicol. 2014;88(2):489-99. https://doi.org/10.1007/s00204-013-1116-3.

129. Rydman EM, Ilves M, Koivisto AJ, Kinaret PA, Fortino V, Savinko TS, et al. Inhalation of rod-like carbon nanotubes causes unconventional allergic airway inflammation. Part Fibre Toxicol. 2014;11:48. https://doi.org/10.1186/s12989-014-0048-2.

130. Enoksson M, Lyberg K, Möller-Westerberg C, Fallon PG, Nilsson G, LunderiusAndersson C. Mast cells as sensors of cell injury through IL-33 recognition. J Immunol. 2011;186(4):2523-8.

131. Abraham SN, St John AL. Mast cell-orchestrated immunity to pathogens. Nat Rev Immunol. 2010;10(6):440-52.

132. Katwa P, Wang X, Urankar R, Wingard CJ, Brown JM. A novel carbon nanotube toxicity paradigm driven by mast cells and the IL-33/ST2 axis. In: the 6 th international conference on nanotoxicology; 2012.

133. Park EJ, Cho WS, Jeong J, Yi J, Choi K, Park K. Pro-inflammatory and potential allergic responses resulting from $B$ cell activation in mice treated with multi-walled carbon nanotubes by intratracheal instillation. Toxicology. 2009;259(3):113-21.

134. Grecco AC, Paula RF, Mizutani E, Sartorelli JC, Milani AM, Longhini AL, et al. Up-regulation of $\mathrm{T}$ lymphocyte and antibody production by inflammatory cytokines released by macrophage exposure to multi-walled carbon nanotubes. Nanotechnology. 2011;22(26):265103.

135. Ling WL, Biro A, Bally I, Tacnet P, Deniaud A, Doris E, et al. Proteins of the innate immune system crystallize on carbon nanotubes but are not activated. Acs Nano. 2011;5(2):730-7.

136. Szebeni J. Complement activation-related pseudoallergy: a new class of drug-induced acute immune toxicity. Toxicology. 2005;216(2-3):106.

137. Gaboriaud C, Thielens NM, Gregory LA, Rossi V, Fontecillacamps JC, Arlaud GJ. Structure and activation of the C1 complex of complement: unraveling the puzzle. Trends Immunol. 2004;25(7):368-73.

138. Ziccardi RJ. The first component of human complement (C1): activation and control. Springer Semin Immunopathol. 1983;6(2-3):213-30.

139. Salvadormorales C, Flahaut E, Sim E, Sloan J, Green ML, Sim RB. Complement activation and protein adsorption by carbon nanotubes. Mol Immunol. 2006;43(3):193-201.

140. Moghimi SM, Hunter AC, Andresen TL. Factors Controlling Nanoparticle Pharmacokinetics: An Integrated Analysis and Perspective. Annu Rev Pharmacol Toxicol. 2012;52(52):481-503.

141. Liu Z, Davis C, Cai W, He L, Chen X, Dai H. Circulation and Long-Term Fate of Functionalized, Biocompatible Single-Walled Carbon Nanotubes in Mice Probed by Raman Spectroscopy. Proc Natl Acad Sci U S A. 2008;105(5):1410-5.

142. De la Zerda A, Zavaleta C, Keren S, Vaithilingam S, Bodapati S, Liu Z, et al. Carbon nanotubes as photoacoustic molecular imaging agents in living mice. Nat Nanotechnol. 2008;3(9):557-62.

143. Ji SR, Liu C, Zhang B, Yang F, Xu J, Long J, et al. Carbon nanotubes in cancer diagnosis and therapy. Biochim Biophys Acta. 2010;1806(1):29-35.

144. Bottini M, Rosato N, Bottini N. PEG-Modified Carbon Nanotubes in Biomedicine: Current Status and Challenges Ahead. Biomacromolecules. 2011;12(10):3381.

145. Hamad I, Christy HA, Rutt KJ, Liu Z, Dai H, Moein MS. Complement activation by PEGylated single-walled carbon nanotubes is independent of $\mathrm{C} 1 \mathrm{q}$ and alternative pathway turnover. Mol Immunol. 2008;45(14):3797-803.

146. Andersen AJ, Robinson J, Dai H, Hunter AC, Andresen TL, Moghimi SM. SingleWalled Carbon Nanotube Surface Control of Complement Recognition and Activation. Acs Nano. 2013;7(2):1108-19.

147. Andersen AJ, Windschiegl B, Ilbasmis-Tamer S, Degim IT, Hunter AC, Andresen $\mathrm{TL}$, et al. Complement activation by PEG-functionalized multi-walled carbon nanotubes is independent of PEG molecular mass and surface density. Nanomedicine. 2013;9(4):469-73

148. Mitchell LA, Gao J, Wal RV, Gigliotti A, Burchiel SW, Mcdonald JD. Pulmonary and systemic immune response to inhaled multiwalled carbon nanotubes. Toxicol Sci. 2007;100(1):203-14.

149. Mitchell LA, Lauer FT, Burchiel SW, Mcdonald JD. Mechanisms for how inhaled multiwalled carbon nanotubes suppress systemic immune function in mice. Nat Nanotechnol. 2009;4(7):451-6.
150. Vlasova II, Sokolov AV, Chekanov AV, Kostevich VA, Vasil'ev VB. Myeloperoxidase-induced biodegradation of single-walled carbon nanotubes is mediated by hypochlorite. Bioorganicheskaia khimiia. 2011;37(4):510-21.

151. Davies MJ, Hawkins CL, Pattison DI, Rees MD. Mammalian heme peroxidases: from molecular mechanisms to health implications. Antioxid Redox Signal. 2008;10(7):1199.

152. Furtmüller $P G$, Jantschko W, Regelsberger G, Jakopitsch C, Arnhold J, Obinger C. Reaction of Lactoperoxidase Compound I with Halides and Thiocyanate. Biochemistry. 2002:41(39):11895-900.

153. Arnhold J, Flemmig J. Human myeloperoxidase in innate and acquired immunity. Arch Biochem Biophys. 2010;500(1):92.

154. Shvedova AA, Kapralov AA, Feng WH, Kisin ER, Murray AR, Mercer RR, et al. Impaired Clearance and Enhanced Pulmonary Inflammatory/Fibrotic Response to Carbon Nanotubes in Myeloperoxidase-Deficient Mice. PLoS One. 2012;7(3):e30923.

155. Kinnula VL. Production and degradation of oxygen metabolites during inflammatory states in the human lung. Curr Drug Targets Inflamm Allergy. 2005;4(4):465-70.

156. Someya A, Nishijima K, Nunoi H, Irie S, Nagaoka I. Study on the superoxideproducing enzyme of eosinophils and neutrophils--comparison of the NADPH oxidase components. Arch Biochem Biophys. 1997;345(2):207.

157. Girtsman TA, Beamer CA, Wu N, Buford M, Holian A. IL-1R signalling is critical for regulation of multi-walled carbon nanotubes-induced acute lung inflammation in C57BI/6 mice. Nanotoxicology. 2013;8(1):17-27.

158. Andón FT, Kapralov AA, Yanamala N, Feng W, Baygan A, Chambers BJ, et al. Biodegradation of Single-Walled Carbon Nanotubes by Eosinophil Peroxidase. 2013.

159. Murphy FA, Schinwald A, Poland CA, Donaldson K. The mechanism of pleural inflammation by long carbon nanotubes: interaction of long fibres with macrophages stimulates them to amplify pro-inflammatory responses in mesothelial cells. Part Fibre Toxicol. 2012;9(1):8.

160. Craig AP, Rodger D, lan K, Andrew M, William AHW, Anthony S, et al. Carbon nanotubes introduced into the abdominal cavity of mice show asbestos-like pathogenicity in a pilot study. Nat Nanotechnol. 2008;3(7):423-8.

161. Renwick LC, Brown D, Clouter A, Donaldson K. Increased inflammation and altered macrophage chemotactic responses caused by two ultrafine particle types. Occup Environ Med. 2004;61(5):442-7.

162. Brown DM, Stone V, Findlay P, MacNee W, Donaldson K. Increased inflammation and intracellular calcium caused by ultrafine carbon black is independent of transition metals or other soluble components. Occup Environ Med. 2000;57(10):685-91.

163. Kang M, Lim CH, Han JH. Comparison of Toxicity and Deposition of NanoSized Carbon Black Aerosol Prepared With or Without Dispersing Sonication. Toxicol Res. 2013;29(2):121-7.

164. Dan E, Abella-Gallart S, Aguerre-Chariol O, Robidel F, Rogerieux F, Boczkowski J, et al. Effect of BSA on carbon nanotube dispersion for in vivo and in vitro studies. Nanotoxicology. 2007;1(4):266-78.

165. Casey A, Davoren M, Herzog E, Lyng FM, Byrne HJ, Chambers G. Probing the interaction of single walled carbon nanotubes within cell culture medium as a precursor to toxicity testing. Carbon. 2007:45(1):34-40.

166. Sager TM, Wolfarth MW, Andrew M, Hubbs A, Friend S, Chen T, et al. Effect of multi-walled carbon nanotube surface modification on bioactivity in the C57BL/6 mouse model. Nanotoxicology. 2014;8(3):317-27.

167. Li R, Xiang W, Ji Z, Sun B, Zhang H, Chong HC, et al. Surface Charge and Cellular Processing of Covalently Functionalized Multiwall Carbon Nanotubes Determine Pulmonary Toxicity. Acs Nano. 2013;7(3):2352.

168. Wang $X$, Zang JJ, Wang H, Nie H, Wang TC, Deng XY, et al. Pulmonary toxicity in mice exposed to low and medium doses of water-soluble multi-walled carbon nanotubes. J Nanosci Nanotechnol. 2010;10(12):8516-26.

169. Hamilton RF Jr, Buford M, Xiang C, Wu N, Holian A. NLRP3 inflammasome activation in murine alveolar macrophages and related lung pathology is associated with MWCNT nickel contamination. Inhal Toxicol. 2012;24(14): 995-1008. https://doi.org/10.3109/08958378.2012.745633.

170. Movia D, Prina-Mello A, Bazou D, Volkov Y, Giordani S. Screening the cytotoxicity of single-walled carbon nanotubes using novel 3D tissuemimetic models. Acs Nano. 2011;5(11):9278-90.

171. Jr RFH, Thakur SA, Holian A. Silica binding and toxicity in alveolar macrophages. Free Radic Biol Med. 2008:44(7):1246-58.

172. Gutierrez-Praena D, Pichardo S, Sanchez E, Grilo A, Camean AM, Jos A. Influence of carboxylic acid functionalization on the cytotoxic effects induced by single wall carbon nanotubes on human endothelial cells (HUVEC). Toxicol In Vitro. 2011;25(8):1883-8. https://doi.org/10.1016/j.tiv.2011.05.027. 